OAK RIDGE
$\frac{\text { NATIONAL LABORATORY }}{\text { MANAGED BY UT-BATTELLE }}$
FOR THE DEPARTMENT OF ENERGY

ORNL/TM-2012/515

\title{
A RETROSPECTIVE TIERED ENVIRONMENTAL ASSESSMENT OF THE MOUNT STORM WIND ENERGY FACILITY, WEST VIRGINIA, USA
}

\section{November 26, 2012}

Rebecca A. Efroymson and Robin J. Day Oak Ridge National Laboratory

M. Dale Strickland

Western EcoSystems Technology

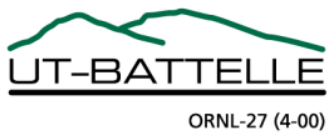




\section{DOCUMENT AVAILABILITY}

Reports produced after January 1, 1996, are generally available free via the U.S. Department of Energy (DOE) Information Bridge.

Web site http://www.osti.gov/bridge

Reports produced before January 1, 1996, may be purchased by members of the public from the following source.

National Technical Information Service
5285 Port Royal Road
Springfield, VA 22161
Telephone 703-605-6000 (1-800-553-6847)
TDD 703-487-4639
Fax 703-605-6900
E-mail info@ntis.gov
Web site http://www.ntis.gov/support/ordernowabout.htm

Reports are available to DOE employees, DOE contractors, Energy Technology Data Exchange (ETDE) representatives, and International Nuclear Information System (INIS) representatives from the following source.

Office of Scientific and Technical Information

P.O. Box 62

Oak Ridge, TN 37831

Telephone 865-576-8401

Fax 865-576-5728

E-mail reports@osti.gov

Web site http://www.osti.gov/contact.html

This report was prepared as an account of work sponsored by an agency of the United States Government. Neither the United States Government nor any agency thereof, nor any of their employees, makes any warranty, express or implied, or assumes any legal liability or responsibility for the accuracy, completeness, or usefulness of any information, apparatus, product, or process disclosed, or represents that its use would not infringe privately owned rights. Reference herein to any specific commercial product, process, or service by trade name, trademark, manufacturer, or otherwise, does not necessarily constitute or imply its endorsement, recommendation, or favoring by the United States Government or any agency thereof. The views and opinions of authors expressed herein do not necessarily state or reflect those of the United States Government or any agency thereof. 


\title{
A RETROSPECTIVE TIERED ENVIRONMENTAL ASSESSMENT OF THE MOUNT STORM WIND ENERGY FACILITY, WEST VIRGINIA, USA
}

\author{
Rebecca A. Efroymson and Robin J. Day
}

Oak Ridge National Laboratory

M. Dale Strickland

Western EcoSystems Technology, Cheyenne, WY

November, 2012

Prepared by

OAK RIDGE NATIONAL LABORATORY

Oak Ridge, Tennessee 37831-6283

managed by

UT-BATTELLE, LLC

for the

U.S. DEPARTMENT OF ENERGY

under contract DE-AC05-00OR22725 
(THIS PAGE LEFT BLANK INTENTIONALLY) 


\section{CONTENTS}

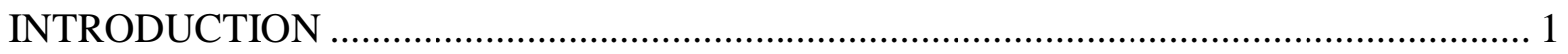

TIER 1: PRELIMINARY SITE EVALUATION .......................................................... 5

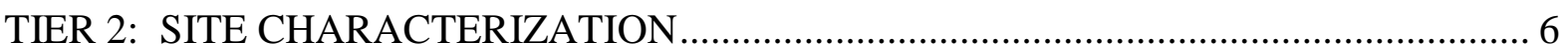

TIER 3: FIELD STUDIES TO DOCUMENT SITE WILDLIFE AND HABITAT AND

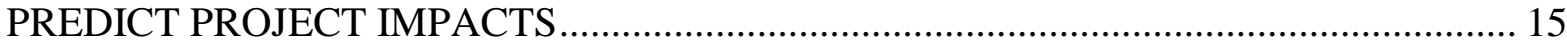

TIER 4: POST-CONSTRUCTION STUDIES TO ESTIMATE IMPACTS ....................... 30

TIER 5: OTHER POST-CONSTRUCTION STUDIES ................................................. 36

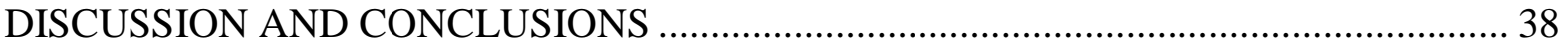

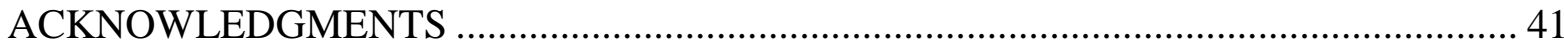

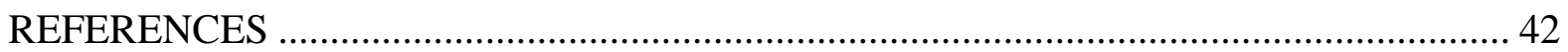


(THIS PAGE LEFT BLANK INTENTIONALLY) 


\section{LIST OF FIGURES}

Figure 1. Helmick Run Bog. Sources: 1) NedPower Mount Storm, 2002, p. 29. 2) USFWS National Wetlands Inventory, Wetlands Mapper at http://www.fws.gov/wetlands/Data/Mapper.html ......................64

Figure 2. Radar sampling station locations and fixed-point survey plot locations, taken from the avian baseline assessment for Mount Storm, Young et al. (2004)...........................................................................................65

Figure 3. Numbers of bat carcasses found at turbines searched daily. Box and whiskers plots show median, lower quartile, upper quartile, and extremes. Asterisks show Turbine 81. For Fall 2008, Spring 2009, and Fall 2009, Turbine 81 was an extreme outlier for bat fatalities, using the conservative definition of three times the interquartile range. Turbine 81 was not included in daily searches in spring or fall of

2011; therefore it is unknown if it would have been an outlier during those seasons......................................66 
(THIS PAGE LEFT BLANK INTENTIONALLY) 


\section{LIST OF TABLES}

Table 1. Species of concern at the Mount Storm Wind Energy Facility

Table 2. Tier 3 wildlife studies at the proposed Mount Storm project site

Table 3. Potential sources of bias and error in fatality estimates in Tier 4 post-construction assessments (Huso 2011), USFWS (2011), Strickland et al. (2011), Johnson et al. (2000), Manville (2009)

Table 4. Estimated fatality rates, Mount Storm Wind Energy Facility, with $90 \%$ confidence limits. Estimation method modified from Shoenfeld (2004) and Erickson et al. (2003). Data from Young et al. (2009a,b; 2010a,b; 2011a,b; 2012a)

Table 5. Estimated bat mortality rates and numbers of individual deaths facility-wide, using modified estimation method from Shoenfeld (2004) and Erickson et al. (2003). Data from Young et al. (2009a,b; 2010a,b; 2011a,b; 2012a)...........................................................................61

Table 6. Bird fatality rates (fatalities/MW/yr) from Mount Storm Wind Energy Facility and nearby wind

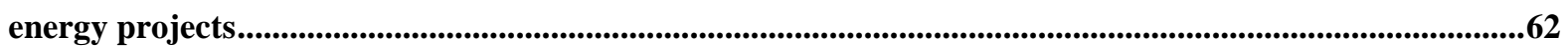

Table 7. Bat fatality rates from Mount Storm and nearby wind energy facilities . .63 
(THIS PAGE LEFT BLANK INTENTIONALLY) 


\begin{abstract}
Bird and bat fatalities from wind energy projects are an environmental and public concern, with post-construction fatalities sometimes differing from predictions. Siting facilities in this context can be a challenge. In March 2012 the U.S. Fish and Wildlife Service (USFWS) released "Land-based Wind Energy Guidelines" to assess collision fatalities and other potential impacts to species of concern and their habitats to aid in siting and management. The Guidelines recommend a tiered approach for assessing risk to wildlife, including a preliminary site evaluation that may evaluate alternative sites, a site characterization, field studies to document wildlife and habitat and to predict project impacts, and post-construction studies to estimate fatalities and other impacts and to better understand causes of adverse impacts or ineffective mitigation. We applied the tiered assessment framework to a case study site, the Mount Storm Wind Energy Facility in Grant County, West Virginia, USA, to demonstrate the use of the USFWS assessment approach, to indicate how the use of a tiered assessment framework might have altered outputs of wildlife assessments previously undertaken for the case study site, and to assess benefits of a tiered ecological assessment framework for siting wind energy facilities. For birds, the conclusions of this tiered assessment are similar to those of previous environmental assessments for Mount Storm. For bats, this assessment found risk to individual migratory tree-roosting bats that was not emphasized in previous preconstruction assessments. Differences compared to previous environmental assessments are related more to knowledge accrued in the past 10 years than to the tiered structure of the Guidelines. Benefits of the tiered assessment framework include good communication among stakeholders, clear decision points, a standard assessment trajectory, narrowing the list of species of concern, improving study protocols, promoting consideration of population-level effects, promoting adaptive management through post-construction assessment and mitigation, and sharing information that can be used in other assessments.
\end{abstract}


(THIS PAGE LEFT BLANK INTENTIONALLY) 


\section{INTRODUCTION}

The primary environmental concern regarding adverse impacts of most wind energy projects has been bird and bat fatalities from collisions with wind turbines (NRC 2007, Arnett et al. 2008). Potential decreases in the abundance of wildlife through displacement by wind farms are also a concern at some facilities (The Wildlife Society 2007, Pearce-Higgins et al. 2009, Garvin et al. 2011, Dahl et al. 2012). Both of these issues affect the viability of some projects within a renewable energy industry that provides clear environmental benefits, such as reduced greenhouse gas emissions, a renewable domestic energy source, and low water usage.

Siting wind energy facilities in the context of uncertain ecological risk is a major challenge (DOE 2008). Wildlife assessments are undertaken by developers to aid in their project planning, to characterize or to minimize effects of wind energy on wildlife and, when appropriate, to fulfill regulatory requirements. These assessments have included "desk-top" siting assessments, site characterization assessments, baseline studies and permitting assessments, post-construction assessments and mitigation evaluation studies. The timing, methods, supporting data, and detail of analysis have varied among wildlife assessments conducted at different sites.

In March 2012 the U.S. Fish and Wildlife Service released "Land-based Wind Energy Guidelines" to assess "potential adverse effects to species of concern and their habitats" (USFWS 2012), henceforth "the Guidelines." The Guidelines recommend a tiered approach for obtaining data to assess risk to wildlife sufficient to make siting and related management decisions. The objectives of this paper are 1) to apply the tiered assessment framework developed by USFWS to a case study, 2) to indicate how outputs of wildlife assessments previously undertaken for the case study site might have been different if a tiered assessment framework had been used, and 3) to assess benefits of a tiered ecological assessment framework for siting wind energy facilities.

The case study site is the Mount Storm Wind Energy Facility in Grant County, West Virginia, USA. Pre-construction environmental assessments were completed in 2004, and post-construction fatality studies were completed in fall of 2011.

Here we use preexisting data and analysis for this wind energy site to demonstrate the tiered assessment framework, retrospectively. We have the benefit of hindsight (i.e., knowing the post-construction collision fatality results before conducting our preconstruction assessment), a growing body of research on impacts of wind energy on birds and bats (e.g., recent emphasis on bat collision fatalities), and avian and bat fatality results for neighboring 
facilities. Thus, this demonstration does not represent our assertions concerning what should have been done in previous wildlife assessments for the site. Rather, we indicate how a tiered assessment would be done for the Mount Storm site, given what we know now. However, because we draw on past assessments, we do not include the participation of stakeholders beyond their previous engagement in the process. The Guidelines recommend early and regular communication with stakeholders including the U.S. Fish and Wildlife Service, state wildlife agencies, and others (USFWS 2012), and the tiers of assessment would be influenced by their input. Our goal with this case study is to provide a real-world example that we believe will assist others in implementing the tiered assessment framework at other wind energy facilities in a straightforward way.

\section{TIERED ASSESSMENT}

A tiered approach is a stepwise approach to environmental assessment that involves "progressive data and resource intensity" (EPA 1998). Tiered approaches have long been recommended for evaluating hazards from new chemicals (Huchon et al. 1979), evaluating human and ecological risks from releases of petroleum (ASTM 1994), and as an option for conducting ecological risk assessments (EPA 1998). Tiered analysis provides an opportunity for evaluation and decision-making at each stage, or tier. The tiered assessment is advantageous when analyses of an extensive number of stressors (e.g., chemicals), sites, species, or scenarios are required, and a method is needed to winnow down the variables to consider in making management decisions about risk and risk avoidance.

A wind energy developer might use the tiered process to evaluate whether to delay or abandon a potential project site, to proceed with development, or to continue collecting information for more detailed analysis. If data are insufficient at any tier to make a reasoned decision regarding the development, more intensive study is conducted in the subsequent tier until the data are sufficient to support analyses necessary for decision making. Tiered approaches related to wind energy development are presumed to focus assessments of wildlife and other resources on making decisions at the earliest tier possible, avoiding needless delay, higher costs and further study. Tiered assessments are also focused on the greatest potential problems while estimating key potential environmental effects as quantitatively as necessary for decision making.

The USFWS Guidelines recommend up to five tiers for evaluating the development of a single project:

Tier 1 - Preliminary site evaluation 
Tier 2 - Site characterization

Tier 3 - Field studies to document site wildlife and habitat and predict project impacts

Tier 4 - Post-construction studies to estimate impacts

Tier 5 - Other post-construction studies

Tier 1 is intended as a landscape-level review and screening of potential sites or a cursory look at a single site, but subsequent tiers are always focused on a single site. Each tier of the Guidelines consists of a set of questions to be answered, along with some suggested methods and metrics to answer them. A much more detailed review of methods and metrics for particular tiers of analysis is presented in Strickland et al. (2011). While the Guidelines are intended for use with an extensive list of "species of concern," they have a particular, but not exclusive, focus on avian and bat impacts. Every recommended question within each tier will not need to be studied in depth for every project. Rather, the process is designed to allow efficiency by using only the resources necessary to gain the information needed, while at the same time providing a framework to ensure that all necessary questions and concerns are addressed. Research that is not site-specific (e.g., mechanistic questions regarding attraction of bats to turbines) is not addressed in any tier. The tiered approach is not necessarily driven by the permitting process (e.g., Tier 1 is almost always conducted outside of a permitting process), but the permitting process will likely influence the type and timing of data collection.

\section{SPECIES OF CONCERN}

Species of concern are defined in the Guidelines based on a combination of susceptibility to wind energy and policy. Susceptibility includes contact with turbines or exposure to other stressors such as habitat reduction or fragmentation, combined with sensitivity to those stressors. Species of concern are species "1) protected by the MBTA [Migratory Bird Treaty Act], BGEPA [Bald and Golden Eagle Protection Act], or the ESA [Endangered Species Act] (including candidate species), designated by law, regulation or other formal process for protection and/or management by the relevant agency or other authority, or that have been shown to be significantly adversely affected by wind energy development; and 2) determined to be possibly affected by the project." Thus, species of concern include rare species; raptors and other migratory birds; other protected species (such as state game species) susceptible to wind energy projects; and, bats. "Species of habitat fragmentation concern," a subset of species of concern, plant communities of concern and even protected areas are also addressed in the Guidelines (USFWS 2012). Species of 
concern are not limited to those for which a population-level effect is likely; effects to individuals are considered as well.

\section{SITE DESCRIPTION}

On August 8, 2002, a newly formed company, NedPower Mount Storm LLC (NedPower), applied to the Public Service Commission of West Virginia (PSC) for a certificate of convenience and necessity to build and operate a wind power facility in Grant County, West Virginia. The site, mainly used for logging and strip mining, extended from east of the Stony River Reservoir along the Allegheny Front to $1.2 \mathrm{~km}$ from Mt. Pisgah (Canterbury 2002). The Allegheny Front is the main ridgeline of the Allegheny Mountains about six kilometers east of the Mount Storm project site and 0.8-1.6 km east of Mount Storm Lake and Stony River Reservoir, extending along a trajectory approximately $216^{\circ}$ northeast to southwest (Young et al. 2004). The site is in the Allegheny Mountains physiographic region and is near the western edge of the Ridge and Valley physiographic province of West Virginia. The dominant vegetation consists largely of mixed hardwoods in the north and hardwood spruce forest in the south (Hall 1983, Canterbury 2002). Where construction was proposed, landscapes consisted of deciduous woodlands and reclaimed mine lands, some of which were recently seeded grasslands and others of which were later successional woodlands (Johnson and Strickland 2003). Elevation ranges from about 800 to $1150 \mathrm{~m}$ (Young et al. 2004).

The proposed project consisted of up to 200 wind turbine generators (300 MW) to be located on a strip of land approximately $0.8 \mathrm{~km}$ wide and $22.5 \mathrm{~km}$ long, running along the Allegheny Front (NedPower Mount Storm LLC 2002). The proposed project area was divided into three sections, the Central Phase, Northern Phase, and Southern Phase.

NedPower proposed first to construct the Central Phase, then subsequently to construct the Northern and Southern Phases. The rotor swept area of the turbines extended from $25 \mathrm{~m}$ to $115 \mathrm{~m}$ above the ground (Young et al. 2003). The total expected area of ground disturbance was less than 80 ha (Johnson and Strickland 2003). The Northern and Central Phases of the project were completed by early 2009, but the Southern Phase was not constructed (see Tier 2 decision point). In this report we apply the tiered assessment approach from the Guidelines retrospectively. 


\section{TIER 1: PRELIMINARY SITE EVALUATION}

Tier 1 has one of three potential objectives: (1) to identify potential development sites within a region based on the potential for significant risk to species of concern or their habitats, (2) to screen a set of potential sites to avoid those with high habitat value, or (3) to begin to evaluate a potential site with respect to risk to wildlife. Tier 1 is an important step that is likely internal to the developer, but that could involve consultation with the U.S. Fish and Wildlife Service and other stakeholders. In this demonstration of the tiered assessment framework, we emphasize the second objective, because the first would require more knowledge of the sites that were considered but eliminated, and the third is undertaken in Tier 2 in more detail. Site selection involves many factors in addition to habitat and wildlife. In the case of the Mount Storm Wind Energy Facility, the proposed site was chosen based on available wind resources and surface access to develop those resources, access to interconnection with the power grid, the limited number of nearby residential areas, and the fact that surface mining and timber operations had already created cleared areas and access roads along the ridge line (Niessen 2002). While a screening process was no doubt conducted to settle on the site for the Mount Storm Wind Energy Facility, the desired location of the project had been selected before any publicly available assessment occurred, and from that time on, no alternative locations were considered. We do not consider Tier 1 further.

In practice, the screening of sites for potential development involves much more than wildlife considerations, as illustrated in the discussion of the Mount Storm site selection process. Because this screening process occurs very early, and usually is internal to the developer, there are few publicly available examples of how this process has worked in the past. The National Environmental Policy Act (NEPA) environmental impact statement (EIS) prepared by the Bureau of Land Management (BLM) for the KENETECH/PacifiCorp Windpower Project, Carbon County, Wyoming (BLM 1995a) provides an illustration of how one developer used this screening process. ${ }^{1}$ The developer evaluated approximately 23 potential development sites during their early planning of the project and using existing data on wind, surface access issues, access to transmission, and other potential resource issues, including wildlife (Steve Steinhour, personal communications). The long list was winnowed down, primarily because of inadequate wind, although one site was dropped because of wildlife issues. This screening resulted in the selection of two sites, Foote Creek Rim and

\footnotetext{
${ }^{1}$ The details of the screening process are described in the draft EIS (BLM 1995b), which is understood to be incorporated in the final EIS.
} 
Simpson Ridge, Wyoming, which were proposed to the BLM for rights-of-way approval. Following a more intense evaluation of these two sites through the EIS (BLM 1995a), the BLM issued a Record of Decision for the SeaWest/PacifiCorp Windpower Project (SeaWest had purchased this project from KENETECH) (DOI 1997), and the developer chose to develop the Foote Creek Rim site in phases.

\section{TIER 2: SITE CHARACTERIZATION}

The goal of Tier 2 is to determine the (qualitative) likelihood that there could be significant adverse effects on wildlife from development at a particular site (USFWS 2012). Tier 2 studies make use of existing information (e.g., from the scientific literature and wildlife agencies) and include at least one reconnaissance-level site visit by a biologist, though more visits may be advisable if major concerns relate to seasonal activities or particular environmental conditions. For example, the Tier 2 site visit would be used to confirm the presence of potential habitat for a listed species when the published information is incomplete, out of date, or exists in too coarse a scale for a particular site to allow the necessary determinations to be made. Surveys to confirm the presence or absence of the protected species would require the rigor of Tier 3. Because Tier 2 studies depend on existing information, Tier 4 fatality reports and other post-construction studies from other wind energy facilities, especially those in similar landscapes or geographic regions, are important. These studies will become increasingly useful for identifying potential risk to species of concern as more facilities are constructed. At this stage, if the developer is satisfied at this point that all Tier 2 question have been adequately answered and risk is low then regulatory requirements may begin to be considered, and potential mitigation actions may be identified. Not all assessments will proceed beyond Tier 2. For example, expansion of an existing facility where impacts have been low might proceed to permitting (if required) and development without proceeding to Tier 3 (USFWS 2012). The six questions included in the Guidelines for Tier 2 are addressed here in order.

This tier includes many elements of environmental assessments for wind energy projects that have previously been termed "Phase I avian risk assessments" and are equivalent to the Site Characterization Studies described in Strickland et al. (2011). This tier also includes some elements of Biological Assessments conducted for threatened and endangered species under Section 7 of the Endangered Species Act.

At the time the application for a permit was made, several steps had already been taken to begin to assess the project's potential environmental impact. Through an 
environmental consulting firm, NedPower had contacted the West Virginia Field Office of the USFWS and the West Virginia Division of Natural Resources (DNR) to inquire about the potential presence or habitat of any endangered or threatened species on their project site (McCoy 2002) and completed a Phase I avian risk assessment (Canterbury 2002).

A comprehensive list of species of concern at the Mount Storm site is presented in Table 1. Included are species of concern that were already known to be present on the site, those which were likely to be present due to suitable habitat and/or demographic range, those recorded on the site during later studies, and species which were later identified as postconstruction fatalities during operation of the wind energy facility, an advantage of hindsight in this study.

\section{Are known species of concern present on the proposed site, or is habitat (including designated critical habitat) present for these species?}

\section{Rare Species and Habitat}

Based on a visit by USFWS to the proposed project site on July 23, 2002, the Service determined that five species of concern could occur in the proposed Mount Storm project location and could potentially be affected by the proposed project (Towner 2002a). All were classified as either endangered or threatened according to the ESA (Table 1). These species were: the endangered Indiana bat (Myotis sodalis); the endangered Virginia big-eared bat (Corynorhinus townsendii virginianus), a subspecies of the Townsend's big-eared bat; the endangered West Virginia northern flying squirrel (Glaucomys sabrinus fuscus), the threatened Cheat Mountain salamander (Plethodon nettingi); and the then-threatened bald eagle (Haliaeetus leucocephalus). No areas in Grant County, West Virginia were designated as critical habitat for any of these species (Hill 2010). The DNR noted that the bald eagle used the project area "for migration and uses Stony River Reservoir and Mount Storm Lake as stopover points for resting and feeding" (Sargent 2002).

The USFWS recommended that surveys be conducted for habitat for both West Virginia northern flying squirrel and Cheat Mountain salamander (Towner 2002a).

Preconstruction reconnaissance studies by local experts were conducted to assess habitat suitability for two potential species of concern, the West Virginia northern flying squirrel and the Cheat Mountain salamander (Table 2). The project area was found to contain three areas of habitat potentially suitable for the West Virginia northern flying squirrel (Michael 2002a). The project area had some of the necessary elements of Cheat Mountain salamander habitat 
as well (Pauley 2002). Additional Tier 3-level studies were recommended to assess further the potential presence and suitability of habitat for these two species.

Also recommended was a study to evaluate whether sufficient Indiana bat habitat would remain after the project was constructed. This would have been part of a Tier 2-level assessment if Indiana bat habitat had been delineated previously in the region. See question 6 for some initial discussion of expected site use by this species.

A number of raptor species were specifically mentioned by the USFWS as potentially susceptible to impact from the Mount Storm Wind Energy Facility, including the northern goshawk (Accipiter gentilis), northern harrier (Circus cyaneus), short-eared owl (Asio flammeus), and northern saw-whet owl (Aegolius acadicus). These species are listed by the West Virginia DNR as "extremely rare" or "very rare" in the state (see Table 1). The USFWS expressed concern that these and related birds of prey might use the project area while hunting and migrating and might be susceptible to collision with towers or rotors (Towner 2002a). However, the site visit that was intended to assess habitat suitability did not confirm the presence of these species at the project site, and further studies, including nest surveys and surveys for raptor activity were recommended for future assessment (equivalent to Tier 3 in the Guidelines).

\section{Other Species of Concern}

Site use by migratory birds and migrating bats is considered in question 6 . Some additional species were noted as species of concern by DNR, for example, the statethreatened Allegheny woodrat (Neotoma magister). Timber rattlesnake (Crotalus horridus) was also identified as a species of concern, but it has no special status in the state. The DNR identified Eastern small-footed bat (Myotis leibii) as a species of concern, and it is currently under status review by the USFWS (USFWS 2011). The DNR indicated that the pink-edged sulphur butterfly (Colias interior), known to be present in the Helmick Run Bog, could be expected to be found throughout the project area because its host plant is blueberry (Vaccinium spp.) (Sargent 2002). This species does not have special status but is considered rare in the region (Table 1 ).

The USFWS also indicated that three summer resident bird species should be studied as potential species of concern: American woodcock (Scolopax minor), common snipe (Gallinago gallinago), and common nighthawk (Chordeiles minor). While these species were known residents of the region, they were not known to be on the project site or to be susceptible to impacts from wind energy.

A benefit of the tiered assessment framework presented in the Guidelines is that it 
encourages the user to consider thoroughly many potentially susceptible species that have been identified from the literature, existing databases and by agencies, or other stakeholders in the tiered assessment and either to carry them forward to the next tier or to screen them out of the assessment.

\section{Does the landscape contain areas where development is precluded by law or designated as sensitive according to scientifically credible information?}

"Examples of designated areas include, but are not limited to: 'areas of scientific importance;' 'areas of significant value;' federally-designated critical habitat; high-priority conservation areas for NGOs; or other local, state, regional, federal, tribal, or international categorizations" (USFWS 2012). Areas with these special designations were not identified by any of the parties involved in the permitting process, development or construction of the Mount Storm project, including the West Virginia DNR or USFWS, or by the authors of this study. The nearest protected area is the Dolly Sods Wilderness Area, which has a boundary approximately $7.7 \mathrm{~km} \mathrm{SSW}$ (along the Allegheny Front) of the current southernmost turbine location.

\section{Are there plant communities of concern present or likely to be present at the site(s)?}

A list of rare plant species which had been recorded as occurring in the Helmick Run Bog at the headwaters of Helmick Run was provided by the West Virginia DNR (Sargent, 2002), and these species are included as species of concern in Table 1. These species include goldthread (Coptis trifolia ssp. groenlandica), hoary sedge (Carex canescens), star violet (Dalibarda repens), balsam fir (Abies balsamea), small cranberry (Vaccinium oxycoccos), and sundew (Drosera rotundifolia). The Helmick Run Bog is within the "Central Phase" of the project boundaries as it was proposed by NedPower in their August 8, 2002 application to the PSC of West Virginia (See Figure 1).

It is not clear that potential impacts to this community were formally addressed during the permitting process for the Mount Storm Wind Energy Facility or whether the Helmick Run Bog area was simply avoided. One purpose of the tiered assessment approach is to ensure that conclusions about probable risk are documented for each species or community of concern, and it is likely that these plant species and Helmick Run would have been formally addressed in the assessment if a structured, tiered approach had been followed.

\section{Are there known critical areas of congregation of species of concern, including, but not}


limited to: maternity roosts, hibernacula, staging areas, winter ranges, nesting sites, migration stopovers or corridors, leks, or other areas of seasonal importance?

\section{Migration Corridor}

The agencies identified the Allegheny Front as a potentially important bird migration area (at least for diurnal migration), and a potential bat migration corridor (Sargent 2002; Towner 2002a). Field studies, equivalent to Tier 3 studies, were recommended to quantify the importance of this area for migration (Johnson and Strickland 2004, Mabee et al. 2004).

\section{Maternity Roost}

A maternity colony of endangered Virginia big-eared bats was known to occupy a cave about $5 \mathrm{~km}$ from the project site on a year-round basis (Sargent 2002). The bats were thought to travel nightly to forage within an eight-to ten-kilometer radius of the colony site, an area which includes the entire project site (Towner 2002a). A more integrated discussion of this species and Tier 2 conclusions are presented below in the response to question 6 .

\section{Winter Range}

Bald eagles have been known to winter in the northern end of Canaan Valley (Towner 2002a), approximately $6.4 \mathrm{~km}$ west of the Mount Storm Wind Energy Facility project site. Existing data were inadequate to characterize the activities and flight locations of this species of concern, and additional bald eagle studies (equivalent to Tier 3 studies) were proposed and subsequently conducted at this site.

5. Using best available scientific information has the developer or relevant federal, state, tribal, and/or local agency identified the potential presence of a population of a species of habitat fragmentation concern?

Habitat fragmentation is the disconnection of habitat area, potentially affecting the genetic or demographic viability of local populations. Habitat fragmentation is a regional concern related to the declining populations of Cheat Mountain salamanders (Bradshaw 2010) and others of the Plethodon genus (Jordan et al. 2009). The West Virginia northern flying squirrel has also been shown to be susceptible to the effects of habitat fragmentation (Sparks 2008). Neither the developer nor an agency indicated that these species were present 
and at potential risk from fragmentation. Therefore, the developer did not assess habitat fragmentation as a potential threat. In retrospect, we find no evidence that their habitat would have been fragmented by the proposed project. However, at this stage of the tiered risk assessment, further Tier 3 study would be needed to determine whether either species was present.

\section{Which species of birds and bats, especially those known to be at risk by wind energy facilities, are likely to use the proposed site based on an assessment of site attributes?}

Table 1 presents a complete listing of bird and bat species that are present in the region or that potentially use the project site. Below we discuss some aspects of habitat that provided evidence about site use by specific bird and bat species.

\section{Migratory Birds}

The Mount Storm project location is within the Allegheny Front, the southeast- or east-facing escarpment in the Allegheny Mountains in southern Pennsylvania, western Maryland, and eastern West Virginia, USA. Passerines are the most common group of species and have comprised the vast majority of avian fatalities at wind energy facilities (Young et al. 2003, Strickland et al. 2011). While passerines typically migrate along a broad front where flight patterns may not be affected by topography (Kerlinger 1995, references in Young et al. 2003), in the opinion of some, the Allegheny Front is a diurnal migration corridor for birds (Hall and Bell 1981, Towner 2002a, Sargent 2002, Canterbury 2002).

The Phase I avian risk assessment indicated that "the biggest operational concern may be with nocturnal migrants, especially Neotropical migrants that depend on the Allegheny Front flyway" (Canterbury 2002). Four of the seven experts interviewed for the Phase I Avian Risk Assessment expressed concerns about impacts to migrating birds (Canterbury 2002). Murray (2002) expressed the specific concern that the entire population of the Kirtland's warbler (Dendroica kirtlandii), a federally endangered species, would likely travel through the region containing the Mount Storm turbines during its migration to and from breeding grounds in Michigan. Moreover, the golden-winged warbler was identified to be a declining species of conservation concern that breeds in the area, and a few areas of suitable habitat were identified, including logged forest areas and right-of-ways (Canterbury 2002). Golden-winged warblers were also among the species identified on a site visit in 2002 (Canterbury 2002). Although proposed locations for the turbines were primarily on the ridge, which was east of the most suitable habitat (Canterbury 2002), turbines were also 
planned adjacent to Stony River Reservoir, which was excellent bird habitat. Because of the concern for this species, a decision was made to conduct a study of golden-winged warbler habitat within the Mount Storm project area during the phase of investigation that corresponds to Tier 3 under the Guidelines (Young et al. 2003). In retrospect the risk to this species probably did not warrant a specific study.

\section{Migrating Bats}

Ten years ago the USFWS (Towner 2002a) and DNR (Sargent 2002) suggested that the operation of the turbines at Mount Storm could impact migrating bats such as hoary bats (Lasiurus cinereus), silver-haired bats (Lasionycteris noctivagans), and eastern red bats (Lasiurus borealis). It is now well understood that many of the bats that are susceptible to wind turbines are species that rely on trees as roosts, most of which migrate long distances (Cryan and Barclay 2009). The vast majority of identified bat fatalities at wind energy facilities have been migratory tree-roosting bats (Erickson et al. 2002, Strickland et al. 2011). Hoary bats, silver-haired bats, and eastern red bats comprise about $77 \%$ of all bat fatalities at 70 wind energy facilities in North America with publicly available fatality records. Based on species distributions (http://nationalatlas.gov/natlas/Natlasstart.asp) and post-construction monitoring results at a wind energy facility at nearby Backbone Mountain (Johnson and Strickland 2003), all three of the migratory tree bat species would be expected to be present at the Mount Storm project site, and are known to susceptible to collision with wind turbines.

\section{Bats of Special Status}

Many lines of evidence in the original Biological Assessment that was undertaken for the Indiana bat and Virginia big-eared bat (Johnson and Strickland 2003) related to the low probability of species or habitat presence at the Mount Storm project site. These points are appropriately described in Tier 2, as they are based on literature review. For example, summer maternal colonies of Indiana bat are thought to be rare in forests of the central Appalachians of Virginia (Brack et al. 2002, Owen et al. 2001, Johnson and Strickland 2003), and because no known hibernacula are in the project area, maternal roost sites are the only habitat areas of potential concern onsite. The most suitable summer habitat consists of wooded areas interspersed with large, open, unforested lands (Gardner and Cook 2002, Johnson and Strickland 2003). In addition, a study of the abundance of species that are related to the Indiana bat and may serve as surrogates for Indiana bat behavior [eastern pipistrelles (tricolor bats, Pipistrellus subflavus), eastern red bats, and little brown bats 
(Myotis lucifugus)], found that the proportion of reproducing bats decreased with elevation in West Virginia (Brack et al. 2002). Moreover, mist net surveys for Indiana bats in the vicinity of the project area (11 sites within $8 \mathrm{~km}$ of Mount Storm) for a highway development project, the Appalachian Corridor H study, did not capture these bats (Angus et al, 2001a, b). Also, the Mount Storm project area has high wind speeds (mean $29 \mathrm{~km} / \mathrm{hr}$ ) that are not very compatible with foraging by bats (P. Clem pers. comm., as cited in Johnson and Strickland 2003).

Thus, a literature review combined with habitat assessments in a reconnaissance visit suggested that Indiana bat would be present at the site in very low numbers, if at all. Subsequent to the literature review conducted by Johnson and Strickland (2003), at least four Indiana bat fatalities have occurred at wind energy plants (one at Duke Energy's North Allegheny Windpower Project in western Pennsylvania, two at Fowler Ridge Wind Farm in Indiana, and one at the Laurel Mountain Wind Power facility in northeastern West Virginia). In addition, white-nose syndrome has spread through much of the northeastern U.S. since 2003 (Frick et al. 2010). Notwithstanding, all three fatality sites were lower in elevation than Mount Storm, and the available research supports the conclusion that Indiana bats are unlikely to occur at the Mount Storm site (e.g., Brack et al. 2002). It is likely, however, that if this site were being evaluated today, more specific Tier 3 habitat surveys or acoustic studies would be recommended.

Little information was available in the scientific literature on the use of summer habitat by Virginia big-eared bat (Adam et al. 1994). The Virginia big-eared bat is nonmigratory and roosts in caves. A cave where several of these bats have been known to reside was $5.6 \mathrm{~km}$ southeast of the project site, and the bats forage and roost up to 8 or $10 \mathrm{~km}$ from the residential cave (Towner 2002a). An additional cave was within $8 \mathrm{~km}$ of the site. Fortytwo caves used by Virginia big-eared bats were within $87 \mathrm{~km}$ of the Mount Storm wind project (Johnson and Strickland 2004). All but two of these were south of the project, indicating that bats would not have to cross the project site to travel between caves (Johnson and Strickland 2004). The project area itself was determined to be unsuitable for Virginia big-eared bat because of the high elevation and high wind speeds (Johnson and Strickland 2003).

Hellhole Cave in Pendleton County, WV, is designated critical habitat for both the Indiana bat and the Virginia big-eared bat (Stihler and Brack 1992) at is about $80 \mathrm{~km}$ from the Mount Storm project site. The cave contains about $45 \%$ of the entire hibernating population of Virginia big-eared bat (Youngbaer 2011) and 80\% of the West Virginia population of Indiana bat (Johnson and Strickland 2003). 


\section{Is there a potential for significant adverse impacts to species of concern based on the answers to the questions above, and considering the design of the proposed project}

Based on the literature, one can now conclude that there is a potential for fatalities of migrating, tree-roosting bats such as hoary bats, silver-haired bats, and eastern red bats. The Phase I avian assessment for Mount Storm concluded that the wind energy facility would "have minimal impacts on birds," with the possible exception of nocturnal migrants and golden-winged warblers (Canterbury 2002). Full consideration of these latter species is deferred to Tier 3.

Indiana bat is unlikely to occur at the project site, but adverse effects cannot be ruled out entirely in Tier 2. Effects on Virginia big-eared bat are unlikely, because a) it is nonmigratory, b) caves are not close to the project site, and c) routes between caves do not include the project site. Also, we know of no Townsend's big-eared bat carcasses that have been identified at wind energy facilities (Johnson and Strickland 2003, Strickland et al. 2011). In general, bat fatalities at wind energy facilities do not involve resident bats foraging or traveling between foraging and roosting areas (Johnson and Strickland 2003; Strickland et al. 2011).

Final conclusions regarding habitat and site use by Northern flying squirrel and Cheat Mountain salamander are deferred until additional Tier 3-level surveys are conducted. Similarly, conclusions regarding risk to raptors are deferred until Tier 3.

Because the Helmick Run Bog area was avoided, the potential for significant adverse impacts to rare plants was determined to be very low.

\section{TIER 2 DECISION PROCESS AND OUTCOME}

Four major outcomes of Tier 2 are possible (USFWS 2012):

1. The information collected in Tier 2 is inconclusive, either because of insufficient data or other uncertainties. The developer should proceed to Tier 3. This is the most likely outcome of Tier 2 (USFWS 2012).

2. Responses to all Tier 2 questions indicate a low probability of significant adverse effects on wildlife. The project may proceed to permitting and construction using best management practices.

3. Responses to Tier 2 questions show a moderate probability that species of concern will be significantly affected. Tier 3 should be undertaken to identify ways to mitigate potential significant adverse effects. 
4. Responses to Tier 2 questions show a high probability that species of concern will be significantly affected, and effects may or may not be mitigated. The project should be abandoned if effects cannot be adequately mitigated.

For most species of concern, the information collected in Tier 2 was not sufficient to determine risk of collision or other effects. Clearly, more study was warranted to estimate impacts on species of concern than the reconnaissance-level studies appropriate for Tier 2. As noted above, although Indiana bat is unlikely to occur in the project area, if the site were being evaluated today, more specific Tier 3 habitat surveys or acoustic studies would be recommended because of the fatalities at other facilities. Also, at this early stage of risk assessment, a decision was made not to develop the southern phase of the project. The location of this phase in mature forest, close to the reservoir that bald eagles used as a stopover point, and closer than the more northern phases of the project to the Indiana and Virginia big-eared bat hibernaculum, Hellhole Cave, were likely contributors to the decision.

\section{TIER 3: FIELD STUDIES TO DOCUMENT SITE WILDLIFE AND HABITAT AND PREDICT PROJECT IMPACTS}

Tier 3 is intended to provide more-rigorous and more-quantitative evaluation of a site to determine potential risk prior to construction (USFWS 2012). This tier includes additional studies that are considered necessary to decide whether to proceed with the project, to modify it, or to abandon it (USFWS 2012). Tier 3 focuses on species of concern that need further study following the limited analyses in Tiers 1 and 2. This step includes field studies that are more rigorous than reconnaissance-level studies. These may range from habitat surveys or the application of a habitat model to land-cover data to field studies of seasonal use of the area by species of concern needing further study. In addition, this is the tier in which potential mitigation measures are considered in more detail, i.e., avoiding, minimizing or compensating for significant adverse effects. For some facilities, compensatory mitigation actions may be designed if predicted significant adverse ecological impacts cannot be otherwise avoided or mitigated. (Compensatory mitigation was not considered necessary and has not been performed for the Mount Storm site.) Also in this step, the scope of postconstruction studies (Tier 4 and/or 5) is determined, which include any studies that may be designed to repeat Tier 3 studies for the purpose of evaluating the accuracy of predicted impacts and mitigation measures. The PSC authorization for construction of the Northern and Central phases of the Mount Storm project required several specific wildlife studies (PSCWV 2003) that are appropriate to include in Tier 3. 
Table 2 lists studies which were conducted at Mount Storm and that are most appropriately conducted as part of Tier 3 . Tier 3 could include some additional studies, as discussed below. The six questions included in the Guidelines for Tier 2 are addressed here in order.

\section{Do field studies indicate that species of concern are present on or likely to use the proposed site?}

As stated in the Guidelines, "in many situations, this question can be answered based on information accumulated in Tier 2." Tier 3 includes more rigorous studies of species presence or absence and habitat suitability than simple reconnaissance studies. Field studies were conducted in the vicinity of the proposed Mount Storm site to search for species that were identified earlier as being of potential concern, based on habitat, records from the literature, and discussions with the USFWS.

As had been recommended by USFWS, field studies included trapping to determine the presence of the West Virginia Northern flying squirrel on the project site (Michael 2002a). Six individuals were found, and all suitable habitat was mapped. A search of suitable habitat for Cheat Mountain salamander failed to locate any individuals (Pauley 2002, Pauley and Watson 2002). Consequently, the salamander was removed from the list of species of concern.

The baseline avian studies for Mount Storm (see question 3 below) were intended to identify which bird species were present in the project area during spring and fall migration (Young et al. 2004). One-hundred sixty-one avian species were identified in diurnal surveys (Young et al. 2004). Passerines comprised $88.5 \%$ of all groups observed, in the spring, and $82.0 \%$ of all groups observed in the fall.

Roadside surveys for golden-winged warblers were conducted in reclaimed, early successional or oil field locations. Four migrants were found but no singing territorial males were observed, nor were breeding warblers found in the spring or summer of 2003 (Young et al. 2004). In addition, eleven warblers were observed during the point count surveys, but vegetation in the project area was too open for typical golden-winged warbler habitat (Young et al. 2004). Therefore, the project was not expected to impact the golden-winged warbler or its habitat. In surveys for American woodcock and common snipe, both species were located in suitable habitat in the project area and outside of it, but in low numbers (Young et al. 2004).

Surveys for breeding raptors included nest surveys and broadcast call surveys. Searches for raptor nests across $20 \mathrm{~km}^{2}$ of the project area were conducted during the 
breeding season. No active raptor nests were found (Young et al. 2004). Because the majority of the nesting habitat was in forests, broadcast calls were used to solicit responses from any breeding raptors. These surveys were conducted at 82 stations within the project area during the first week of June 2003. One barred owl was observed.

In fifteen roadside surveys for wintering bald eagles, $34 \mathrm{~km}$ of road were driven around Mount Storm Lake, Stony River Reservoir, and other areas in each survey. A single eagle was observed approximately $1.6 \mathrm{~km}$ from a proposed turbine site, and four others were sighted about $2.4 \mathrm{~km}$ from a southern proposed turbine site that was never built (see Tier 2 Decision Process and Outcome) (Young et al. 2004). Other raptors observed in the surveys are reported in Young et al. (2004).

Habitat suitability for Indiana bat and Virginia big-eared bat at the project site was also considered, though presence or absence of Indiana bats could not be determined definitively (see Tier 2 and question 3 for details). Acoustic monitoring is now recommended for determining the presence of rare bats in suitable habitat (Kunz et al. 2007a, Strickland et al. 2011, USFWS 2012), but it was not used in the Biological Assessment for rare bats at Mount Storm Wind Energy Facility as the habitat was determined to be nonsuitable. Mist-netting, often combined with acoustic monitoring, is sometimes required by state agencies or the USFWS to determine the presence of threatened or endangered bats.

\section{Do field studies indicate the potential for significant adverse impacts on affected population of the species of habitat fragmentation concern?}

No species of habitat fragmentation concern were identified by the agencies during agency discussions mentioned earlier (equivalent to Tier 2) in this case study. Furthermore, no species known to be of habitat fragmentation concern at other sites were found during preconstruction field studies equivalent to Tier 3).

\section{What is the distribution, relative abundance, behavior, and site use of species of concern identified in Tiers 1 or 2, and to what extent do these factors expose these species to risk from the proposed wind energy project?}

The spatial and temporal distribution of species can determine risk of collision, displacement, fragmentation and other risks. Spatial distribution includes airspace as well as ground location (USFWS 2012). Where comparable methods and metrics are used, plots or even sites may be compared (Strickland et al. 2011, USFWS 2012). The probability of collision with turbines is likely related to use of the area (for migration or habitat) and 
behavior, which may include flight at the height of turbine blades, avoidance or attraction to turbines (Young et al. 2003, NRC 2007), and migration patterns and directions (Mabee et al. 2006). Relative abundance by species is also useful to evaluate species-specific collision risk.

\section{Bird Distribution, Abundance, Behavior, and Site Use}

The Guidelines recommend diurnal avian activity surveys, including point counts, transect surveys, and observational studies, all including vertical data (USFWS 2012). Preconstruction nocturnal studies are advisable if the site is a migratory corridor or may attract nocturnal birds (USFWS 2012). Counts should be distributed across the project area. Mistnetting is not recommended by the Guidelines as an approach for assessing risk of collision of turbines with birds (though it can provide evidence regarding habitat suitability). It does not give an estimate of relative species abundance, nor is it feasible at the heights of the rotor-swept zone (Strickland et al. 2011, USFWS 2012).

Based on permit specifications and agency recommendations, several preconstruction bird studies were conducted at Mount Storm consistent with the intended rigor of Tier 3 in the Guidelines. These were included in the Baseline Avian Studies Mount Storm Wind Power Project, Grant County, West Virginia, and included spring and fall diurnal surveys of migrant birds, surveys for woodcock and snipe, a habitat study for golden-winged warblers, surveys for breeding raptors and wintering raptors including bald eagles, and a fall nocturnal radar study (Young et al. 2004). Point count and radar surveys were conducted in part to test hypotheses regarding broad front migration and responses of migrating birds to topography (Figure 2). It should be noted that the areas sampled in diurnal and nocturnal surveys were not comparable, so the counts are not comparable.

Diurnal point count surveys (variable circular plots) were conducted in the spring and fall of 2003 to collect baseline data regarding avian species occurrence, relative abundance and behavior (Young et al, 2003; Young et al, 2004). Methods for point count surveys are in Reynolds et al. (1980) and Bibby et al. (1992). Counts were conducted twice per week between April 29 and June 13, 2003, and from August 14 to October 15, 2003, at 70 locations along transects parallel to the ridgeline (Young et al. 2004). The surveys identified bird species (see question 1, Tier 3), documented the locations of individual observations, and estimated flight heights to assess levels of activity within the rotor-swept zone. The duration and frequency of surveys were designed to meet permit requirements by sampling during both migration seasons, all weather conditions, and at different times of day. It is important to note that the decision to focus on spring and fall migration was made because 
the risk was assumed to be much higher for migrating birds, compared to resident breeding birds.

To standardize avian use data so that comparisons could be made among locations, time of day, seasons, and other studies in similar habitats, only observations within $50 \mathrm{~m}$ of the survey point were counted. The most abundant species using the project area in the spring were American crow (Corvus brachyrhynchos), red-winged blackbird (Agelaius phoeniceus), red-eyed vireo (Vireo olivaceus), eastern towhee (Pipilo erythrophthalmus), and ovenbird (Seiurus aurocapilla) (Young et al. 2004). In the fall, based on site use, the most abundant species were unidentified warbler, American crow, cedar waxwing (Bombycilla cedrorum), blue jay (Cyanocitta cristata), and chipping sparrow (Spizella passerina) (Young et al. 2004). In each 10 minute survey, a mean of 4.8 passerines were observed in the spring and 5.7 in the fall (Young et al. 2004). Passerine use was somewhat higher in the far northern and central areas of the project area than in the southern portion, both in spring and fall (Young et al. 2004). For passerines, the highest use of the site was in early June. Passerine use varied temporally during the fall season with several days with peaks of activity. Passerine use decreased during precipitation events and slightly during high cloud cover, but correlations between avian use and precipitation or maximum temperature were not observed (Young et al. 2004). Use by these species was highest in areas with lowest canopy cover, but use by individual species varied (Young et al. 2004). Raptor use increased slightly as spring progressed and increased as the fall progressed and peaked during midday (Young et al. 2004).

Because night migrating songbirds were of particular concern, as would later be indicated in Kunz et al. (2007a), portable X-band marine radar systems were used at five locations within the project site to determine passage rates, flight direction and altitude of targets passing over the site at night. The term "targets" is used here because these systems cannot distinguish birds from bats. In addition, this radar survey was specifically designed to test three hypotheses regarding songbird migration (Mabee et al. 2004). The first was to collect baseline information regarding flight directions, migration passage rates, and flight altitudes with respect to the Allegheny Front, of nocturnal passerine migrants in the fall of 2003. The second was to determine if nocturnal migrants concentrate along the Allegheny Front in the project area. The third was to quantify variation in the number and altitude of migrants within the potential development area.

The relative abundance of fall nocturnal migrants was estimated through portable marine radar, under the assumption that most targets were birds. The average passage rate in fall of 2003 was 199 targets per kilometer of migratory front per hour (Table 2). Daily measured rates varied greatly from 8 to 852 targets per km per hour (Mabee et al. 2004, 
Mabee et al. 2006), with the mean hourly passage rate greater than 400 targets per $\mathrm{km}$ on nine nights (Young et al. 2004). "Passage rates were not significantly different between the central and the northern sampling stations for concurrent sampling sessions, but were statistically different between the central station and the western, southern, and eastern stations" (Young et al. 2004). Eighty-two percent of radar targets moved toward the south with $51 \%$ of the directions between 135 degrees and 225 degrees (Young et al. 2004). There was no correlation between diurnal use and nocturnal radar passage rates for one- or two-day periods (Young et al. 2004).

Flight altitude was recorded in both diurnal point count and nocturnal radar surveys. The turbines at Mount Storm were expected to have a rotor-swept range from approximately 25 to 125 meters above ground level (AGL). Overall, birds identified in daytime point count surveys were reported as flying within the rotor-swept zone $38 \%$ of the time. However, that percentage varied greatly between the large population of passerines (with $32 \%$ within the zone) and the much smaller population of flying raptors (78\% of which were within the rotor-swept zone) (Young et al. 2003, Young et al. 2004). Nocturnal migrants were observed through radar to have an average flight altitude of 410 meters AGL (ranging from 214-769 m AGL daily mean altitude) during the study period, with $13 \%$ of the targets flying within or below the rotor-swept zone (Mabee et al. 2004.) (Notably, if figures for flight altitudes at sites in Pennsylvania had been transferred to this site with no new field studies, the proportion of birds in the rotor-swept zone would have been underestimated by half - see figures in Mabee et al. 2006). The altitudes of targets differed between the central station on the Allegheny Front and the valley station to the east. Percentages of birds flying within the rotor-swept area in diurnal point count studies and nocturnal radar studies are not comparable, because the latter study included a much broader vertical area.

The objectives of the radar study also included a question regarding the importance of the Allegheny Front for migration. In the diurnal surveys at the central station, $49.7 \%$ of birds approached and crossed the ridge, and $45 \%$ did not approach the ridge; an additional $5.3 \%$ approached and turned more than $10^{\circ}$ before crossing, or turned and did not cross (Young et al. 2004). Moreover, at the central site mean flight direction of targets west of the ridge did not differ from that for targets east of the ridge (Young et al. 2004). It was concluded that most nocturnal migrants did not fly along the Allegheny Front during migration, at least at the scale of radar observations (Mabee et al. 2004, Mabee et al. 2006, Young et al. 2004). Radar targets do not deviate much from flight paths when passing over the ridge, and migration patterns were not related to topography (Mabee et al. 2004).

Based on diurnal bird use results, the project area did not appear to be a site that would attract or concentrate spring or fall migrants (Young et al. 2004). Moreover, "analysis 
of spatial and temporal avian use of the site did not indicate that any location, day, time of day, or season received substantially greater bird use and therefore may result in greater exposure or risk to birds" (Young et al. 2004).

\section{Bat Distribution, Abundance, Behavior and Site Use}

Depending on the site, bat survey methods recommended by the Guidelines include acoustic monitoring to determine site use and activity level, roost searches and exit counts to gather data about local colonies, and possibly radiotelemetry or radar to evaluate activity and movement patterns. These methods are not recommended for every site or all species. For example, radio-telemetry is most often used for studies of Indiana bat. Mist-netting for bats, while required by agencies in some locations (and useful for determining species presence), is not recommended by the Guidelines as an indicator of levels of species use of a site or risk of collision because 1) the project area may not be suitable for capturing bats and offsite areas may not reflect use of the project area and 2) mist-netting is not feasible at the height of the rotor-swept zone (Strickland et al. 2011, USFWS 2012). Indeed, no quantitative relationship has been found between preconstruction bat activity and post-construction fatalities (Johnson and Strickland 2003, Kunz et al. 2007a), although ongoing studies that include acoustic monitoring for bat activity and fatality surveys should help quantify a relationship, if it exists.

A Biological Assessment was conducted for two federally endangered bat species, Virginia big-eared bat and Indiana bat (Johnson and Strickland 2003). The Virginia bigeared bat was eliminated as a species of concern in Tier 2. In general, the project area was determined not to be suitable habitat, based on Tier 2-level literature reviews and summaries of previous field studies. However, the Biological Assessment included site-specific habitat studies for Indiana bat (appropriate for Tier 3), finding that "there is substantial habitat for Indiana bat within $3.2 \mathrm{~km}$ of the project," including shagbark hickory trees, a tree species that is often used for roosting by Indiana bat, but these nearby habitats were at lower elevation than the project area (Johnson and Strickland 2003). Moreover, while no Indiana bat hibernacula are documented in Grant County, two caves are about $29 \mathrm{~km}$ south or southwest of the Mount Storm site. An additional 21 caves used by Indiana bat are within $145 \mathrm{~km}$ of the site (Johnson and Strickland 2004). The direction of migration of Indiana bats from West Virginia hibernacula to summer breeding grounds is unknown (references in Johnson and Strickland 2004). However, investigations involving radio-telemetry of migrating Indiana bats in Pennsylvania and New York found that bats generally follow a straight line that is independent of topography or other land features. 
The supplement to the Biological Assessment for Indiana bat and Virginia big-eared bat summarized data collected on bat use of the Mount Storm project area during the fall 2003 nocturnal avian radar study (Johnson and Strickland 2004). Spotlight surveys could distinguish birds from bats at up to $100 \mathrm{~m}$ AGL. Also, moon-watching surveys were conducted to distinguish bats from birds. Of 88 targets that were positively identified, only six $(7 \%)$ were bats. These data "suggest that the Mount Storm area is not within a major bat migration corridor." Bats (20-25 individuals) were also observed on one date flying at 1030m AGL. Visual surveys undertaken during the nocturnal radar study (Mabee et al. 2004) showed low use of the project ridgeline by bats, with bats observed on only 5 of 71 nights (7\%) that surveys were conducted (Johnson and Strickland 2004). The investigators concluded that valley bottoms in the vicinity of the project area may be used as travel corridors by migrating bats (Johnson and Strickland 2004).

Given that migratory tree-roosting bats make up a high proportion of bat fatalities and wind facilities (see Tier 2 discussion), some researchers hypothesize that some species of bats may be attracted to turbines (Kunz et al. 2007b, Horn et al. 2008, Cryan et al. 2008). Pre- and post-construction acoustic monitoring for bats could provide data to evaluate potential attraction at this and other sites. If a tiered risk assessment framework had been in use at the time of the Biological Assessment for the Mount Storm project, this issue would have been considered in more detail, and it is possible that this point would have been pursued and further site-specific bat studies conducted.

\section{What are the potential risks of adverse impacts of the proposed wind energy project to individuals and local populations of species of concern and their habitats? (In the case of rare or endangered species, what are the possible impacts to such species and their habitats?)}

Adverse impacts can occur if an individual or population is exposed to a stressor and is susceptible. Questions 1 and 3 deal with species presence and site use, and if a species is not present, there is no potential for an adverse impact from development or collision with turbines. If the species is present, there must be some susceptibility to turbines or other stressors, or there can be no adverse effect. Risk of collision is related to species use, behavior, environmental factors, and turbine management. More specific factors include the location of birds or bats within the rotor swept area, as well as flight speed and direction, wind speed and direction, weather, avoidance behavior, and attraction behavior (Young et al. 2004, Kunz et al. 2007a, Strickland et al. 2011). 


\section{Rare Plants}

See Tier 2.

\section{Bird Collision}

Collision risk models are sometimes used to predict fatality rates for birds at wind energy facilities (Tucker 1996, Podolsky 2004, Band et al. 2006, Strickland et al. 2011). Their use has been recommended when there is little empirical data on collision risk for particular species or groups of species (Podolsky 2004, Strickland et al. 2011). These models tend to consider the number, type and size of turbines; spatial pattern of turbines; and wind speed and direction, as well as species properties such as passage rates, flight height, flight speed, and avoidance behavior (Strickland et al. 2011).

The Baseline Avian Studies report for Mount Storm (Young et al. 2004) presented an empirical model of nocturnal migrant mortality based on site-specific passage rate and fatality rate from a nearby facility. ${ }^{2}$ Young et al. (2004) based their model on five assumptions:

- The project site covers about 10 kilometers of migratory front, across the east-west axis

- The mean passage rate of 199 targets $/ \mathrm{km} /$ hour determined from radar is representative of migrating birds moving through the area

- The mean passage rate during the study period of 45 fall nights is representative of the entire fall migration period

- The fall migration lasts from August 1 to November 1 (92 nights)

- One night equals an average 10 hours of migration time.

These assumptions led to an estimate of 1,830,800 birds passing over the Mount Storm project site during the entire fall migration. Based on the radar study, $16 \%$ of those would have been flying below $125 \mathrm{~m}$ AGL, placing them within the elevation range of the rotor-swept zone. Thus, Young et al. (2004) estimated approximately 293,000 birds would have passed through the rotor-swept zone of the entire facility during the fall migration

\footnotetext{
2 Two other preconstruction estimates of avian mortality were made. R. Canterbury gave an estimate of predicted annual bird mortality for the Mount Storm Wind Power Project during his testimony at the PSC hearing but did not state the basis for or reasoning behind this estimate (Canterbury, Nov. 18, 2002). C. Robbins offered a different mortality model in "Comments on Proposals for Windpower Facilities on Allegheny Ridges" (Robbins, 2002). His was based on data from three previous studies that were not specific to this site.
} 
period.

However, not every bird that flies through the project area at below $125 \mathrm{~m}$ AGL flies through the rotor-swept area and not every bird that flies through the rotor swept area is killed by the rotor blades. To estimate the fraction of fatalities among birds flying through the rotor-swept area, Young et al. (2004) assumed that the per-turbine fatality rate at Mount Storm would be similar to that observed at nearby Mountaineer Wind Energy Center in Tucker County, West Virginia (then called the Backbone Mountain Wind Plant). Turbine height at this facility was about $116 \mathrm{~m}$ (Kerns and Kerlinger 2004). Young et al. (2004) noted that the Mountaineer Wind Energy Center had a mortality rate of 2.37 birds per turbine per fall season (Kerns and Kerlinger 2004). This was the only mortality rate based on postconstruction monitoring available anywhere in the region at that time. If mortality at Mount Storm were similar, 200 turbines would result in about 474 bird fatalities during the fall migration. That represents only $0.16 \%$ of the number calculated to be flying below $125 \mathrm{~m}$ AGL (Young et al. 2004). ${ }^{3}$

The Baseline Avian Studies report concluded "Based on the results of these studies, there is no evidence that the Mount Storm wind project will pose a risk to migrant birds greater than other studied wind farms" (Young et al. 2004).

\section{Bat Collision}

Potential risks of adverse impacts of the Mount Storm wind energy project to bats were not estimated quantitatively because Indiana bat fatalities had not yet been found at any facilities, and collision risk was determined to be low (see below). Moreover, at several wind plants where data were available, there is no relationship between bat activity or site use and fatality rate (Johnson and Strickland 2003). "A fundamental gap in our current knowledge of preconstruction assessment of risk is that no linkages exist between preconstruction assessments and post-construction fatalities for nocturnal wildlife" (Kunz et al. 2007a). Kunz et al. (2007b) offer several hypotheses regarding why insectivorous bats are killed at wind energy facilities. When the mechanisms of mortality are better understood, better models of fatalities can be developed.

In the absence of a confirmed mechanism and related model of mortality, one can use

\footnotetext{
${ }^{3}$ This estimate of bird fatalities does not use the site-specific information on passage rate. However, if another wind energy facility were built in the region, it would be reasonable to multiply $0.16 \%$ by the estimate of birds flying below 125AGL to estimate fatality, and this estimate would make use of both data from Mountaineer Wind Energy Center and Mount Storm.
} 
the fatality rates of a nearby facility as a pre-construction estimate of bat fatalities at Mount Storm. The Mountaineer Wind Project is located $27 \mathrm{~km}$ west of the Mount Storm Wind Project. The majority (66.5\%) of the fatalities found at Mountaineer between April 20 and November 9, 2003 were migratory tree bats, including eastern red bats, hoary bats, and silver-haired bats (Kerns and Kerlinger 2004, Johnson and Strickland 2004). Eastern pipistrelle comprised $18.3 \%$ of fatalities and little brown bat comprised $12.6 \%$ of fatalities; while fatalities have been variable across the country, these and similar species (e.g., western pipistrelle) typically comprise a relatively small percentage of bat fatalities at other US facilities (Kerns and Kerlinger 2004, Johnson and Strickland 2004). Almost all of the fatalities at Mountaineer in 2003 occurred between mid-August and the end of September, consistent with the timing of mortality at other US wind energy facilities (Johnson and Strickland 2004). The estimated number of bat fatalities during the study period was 2092 bats or 31.70 bats per MW (47.53 bats per turbine) (Kerns and Kerlinger 2004). Values were corrected for searcher efficiencies and carcass removal times for birds, introducing some uncertainty (Kerns and Kerlinger 2004). Using the above data from Mountaineer for 132 turbines at Mount Storm, the number of fatalities would be about 6274. However, the Mount Storm project area does not appear to be in a migratory corridor for bats; visual surveys undertaken during the nocturnal radar study (Mabee et al. 2004) showed low use of the project ridgeline by bats, with bats observed on only $7 \%$ of the nights that surveys were conducted (Johnson and Strickland 2004). Therefore, the per-turbine fatality rate at Mountaineer Wind Energy Center is likely a high estimate of the fatality rate at Mount Storm.

As part of the supplement to the Biological Assessment for Indiana bat and Virginia big-eared bat, existing evidence related to bats was evaluated to determine the likelihood of collision mortality of these endangered species. The evidence included fatality data for these and related species for other sites, in particular the nearby Mountaineer Wind Energy Center; data on use of the Mount Storm site by bats; telemetry studies of migrating Indiana bats in Pennsylvania and New York; and, locations of direct pathways between hibernacula of Virginia big-eared bat. The final three lines of evidence regard potential site use and were addressed in questions 1 and 3 but are summarized here as well.

No fatalities of Indiana bat or Virginia big-eared bat were found at the Mountaineer Wind Energy Center in 2003 (Johnson and Strickland 2004). (Three such fatalities have been found since then at Duke Energy's North Allegheny Windpower Project in western Pennsylvania, Fowler Ridge Wind Farm in Indiana, and the Laurel Mountain Wind Power Facility in northeastern West Virginia.)

The bat fatality data described above from Mountaineer Wind Energy Center were 
evaluated for consideration of endangered species at Mount Storm. Johnson and Strickland (2004) noted that the migration patterns and timing of Indiana bat are similar to those of the little brown bat and eastern pipistrelle. However, fatality data at other sites, including the Mountaineer Wind Energy Center, indicated that Indiana bat was less susceptible to turbines than little brown bats, given the relative population numbers of the two species and the lack of any identified Indiana bat carcasses. The difference in susceptibility between the related bat species may relate to behavior, migration routes, or other factors (Johnson and Strickland 2004).

Investigations involving radiotelemetry of migrating Indiana bats in Pennsylvania and New York found that bats follow a straight line that is independent of topography or other land features. The vast majority $(95 \%)$ of caves used by Virginia big-eared bat that occur in the region are south of the project area, and bats traveling from one to another would not have to cross the project area. Therefore, "the possibility of a take of an Indiana bat or Virginia big-eared bat" was believed to be "very remote" (Johnson and Strickland 2004).

\section{Displacement of Raptors}

The project is not likely to displace nesting raptors, as no active raptor nests were found on the site.

\section{How can developers mitigate identified significant adverse impacts?}

Mitigation actions can be undertaken by adjustments to siting, construction schedules, operating schedules, and the design of turbines and wind energy facilities. Tier 3 studies are intended to characterize and to quantify risks sufficiently to support decisions about the need for and the design of mitigative measures (USFWS 2012). Information about species distributions and site use helps developers site individual turbines so as to minimize otherwise significant impacts to species of concern. The design of individual turbine locations is referred to as "micro-siting." Moreover, construction can be scheduled so as to minimize potential effects. Correlations of environmental factors with fatalities or other adverse effects can lead to some mitigation measures. For example, recent fatality studies at wind energy facilities in other regions have shown a relationship between low visibility and mortality during migration (e.g., Criterion Wind Project, Maryland, Young et al. 2012b). Thus, if avian or bat collisions are correlated with particular weather patterns and the risk is considered significant enough to warrant mitigation, then turbine use might be curtailed during those periods. However, further mitigations require some understanding of causation, 
e.g., the mechanisms by which some migratory tree bats are at greater risk at some times. Without this knowledge, optimum mitigation measures cannot be identified or developed. In addition to these mitigation measures, wind energy developers should use the Best Management Practices described in USFWS (2012). Future engineering technologies may be developed to reduce collisions, as causes of collisions are better understood.

Mitigations for significant risk to birds is currently less well developed for birds than bats, primarily because of the lower fatality rates. However, measures might include micrositing, limiting activities seasonally, or limiting use of attractive equipment. The conclusion of the Avian Baseline report for Mount Storm was that the overall risk was thought to be low and no specific turbine patterns would reduce risk over any other patterns within the Mount Storm project site (Young et al. 2004). Therefore, turbine positions were not altered to reduce the probability of avian collision. At the nearby Mountaineer Wind Energy Center, sodium vapor lights were implicated in an avian mortality event (Kerns and Kerlinger 2004). The guidelines recommend that developers "minimize use of high intensity lighting, steady-burning, or bright lights such as sodium vapor, quartz, halogen, or other bright spotlights."

Although the use of the project site by Indiana bats was considered very unlikely, the USFWS earlier suggested scheduling of tree removal for the season when the bats tend to hibernate as a mitigation measure to avoid incidental take of roosting Indiana bats (i.e., November 15 to March 31) (Towner 2002a).

Recent studies have observed timing and environmental correlations with bat fatalities and identified some potential mitigation measures for bat collisions with turbines. Nearly $90 \%$ of bat fatalities at US wind plants occurred from mid-July through midSeptember (Johnson and Strickland 2003, Arnett et al. 2008). Moreover, bat mortality increases immediately before and after storm fronts (Kerns et al. 2005). But the most important environmental correlation with bat fatalities may be low wind speed. Bats are known to be more active during times of low wind speed and less active when the speed increases (for example, above $5 \mathrm{~m} / \mathrm{s}$ ). Wind turbines generally only produce electricity when the wind speed is greater than about $3.5 \mathrm{~m} / \mathrm{s}$. When the wind speed is too low to produce energy, some turbines continue to slowly rotate and some turbine blades "feather," meaning they pitch parallel to the wind direction, so that, while free to move, they move only very slowly. At two wind energy plants in West Virginia and Pennsylvania (Mountaineer Wind Energy Center and Meyersdale Wind Energy Center near Meyersdale, PA), most bat fatalities occurred on nights with low wind, when turbine blades were generally moving at or near the full operational speed of $17 \mathrm{rpm}$ (Kerns et al. 2005).

A study conducted at Casselman Wind Project in Somerset County, Pennsylvania, 
about $74 \mathrm{~km}$ north of Mount Storm, found that increasing turbine cut-in speed to $5.0 \mathrm{~m} / \mathrm{s}$ during the fall migration season was associated with a reduction of at least $44 \%$ in nightly bat mortality (Arnett et al. 2011), corroborating results of a previous study testing similar mitigation options for bat mortality (Baerwald et al. 2009). Reducing rotor speed at low wind speeds minimizes bat fatalities during the fall migration period and may have only negligible effects on power generation (Arnett et al. 2011). This speed reduction can be accomplished by "feathering" turbine blades, i.e., (depowering and orienting blades so that they are not oriented to catch wind) or by altering the turbine cut-in speed (wind-speed trigger point where they begin to turn) (Baerwald et al. 2009).

If this information had been available prior to construction of the Mount Storm plant, an option for mitigation would have been to change the turbine "cut-in speed," i.e., keeping rotor blades feathered until wind reaches a specific minimum speed, such as 5.0 or $6.5 \mathrm{~m} / \mathrm{s}$. [Benefits of this mitigation were evaluated during fatality studies at Mount Storm (Young et al. 2011). See Tier 4.] However, Kerns and Kerlinger (2004) found no strong correlations between wind speed and bat carcasses at the Mountaineer Wind Energy Center Weller and Baldwin (2012) recommend using multiple environmental variables in addition to wind speed to predict bat use of a project area and to guide the curtailment of operations, and as these variables are identified, the optimal mitigations may change somewhat.

The primary micrositing decisions for Mount Storm were based on the outcome of the West Virginia northern flying squirrel field studies. Other potential sites for avoidance, including maternity roosts and hibernacula for bats, nesting sites, migration stopovers, and leks, were not identified on the site.. To protect the habitat of the endangered West Virginia northern flying squirrel, a 150-foot buffer of suitable habitat was created. The 150-foot buffer was the distance required in the species recovery plan (USFWS 2001). The purpose of the golden-winged warbler habitat study, according to the PSC permit, was to aid in micrositing as well (Young et al. 2004). However, because breeding golden-winged warblers were not found on the project site, no mitigations were thought necessary.

As discussed in Tier 2, the DNR expressed some concerns about rare plants in Helmick Run Bog (Sargent 2002), so these were included as species of concern in Tier 2 and Table 1. No turbines or other construction was planned within 500 meters of Helmick Run, nor within two kilometers of its headwaters, the location of Helmick Run Bog. It is likely that the bog was purposefully avoided because of the wetlands and rare plants.

\section{Are there studies that should be initiated at this stage that would be continued in post- construction?}


The USFWS (2012) provides examples of two types of these before-after studies. One is evaluations of the efficacy of mitigation measures and the other is the characterization of demographic parameters of local populations for the purpose of evaluating populationlevel effects. Population-level effects could be estimated in the context of cumulative risk from multiple facilities, white-nose syndrome, loss of habitat, pesticides, etc., though these studies are expensive, and no single developer could absorb the cost. In addition, preconstruction mortality monitoring of birds and bats in Tier 3 could provide baseline data to compare with post-construction mortality rates, but time and financial costs could be high, compared to the benefit.

\section{TIER 3 DECISION PROCESS AND OUTCOME}

The conclusion of Tier 3 consists of a decision by the developer and/or permitting authority concerning whether and how to develop the project. The decision also determines the initial duration of fatality monitoring, based on the probability of significant adverse impacts (USFWS 2012). Following Tier 3 for Mount Storm, concerns about the following species are eliminated (Table 2):

- Cheat Mountain Salamander

- Indiana bat

- Virginia Big-eared bat

- Golden-winged warbler

- Raptors

- American Woodcock

- Common Snipe

Regarding risk to migrating birds, passerine fatalities are anticipated to be low relative to the number of birds exposed, but in larger numbers than fatalities to other groups, as at other wind energy facilities. However, there was no evidence to suggest that the project site would cause more fatalities than other wind energy facilities in the region. Nor was there evidence to suggest that some planned turbine locations would cause more fatalities than other locations. The best scientific data available demonstrated that $84 \%$ of nocturnal migrants flew above the reach of the wind turbines during the study period, and that there was no evidence supporting the hypothesis that nocturnal migrants concentrate along the Allegheny Front during migration.

Information came to light in the bat biological assessments that revealed potential impacts to individuals of three migratory tree bat species, which have been added to the list 
of species of concern. These were the hoary bat, Eastern red bat, and silver-haired bat. If the tiered assessment had been performed with current knowledge, there would be an evaluation of the significance of this impact. Given the subjective definition of "significant" in the USFWS guidelines (USFWS 2012, see page 63), the impact is probably not significant, but there is uncertainty. Thus, it could be concluded that "development of the site has a moderate to high probability of significant adverse impacts without proper measures being taken to mitigate those impacts" (USFWS 2012, see p 33) and that at least two years of fatality studies are required. Notwithstanding, the significance of the impact is the primary source of uncertainty. Ironically, the permit for this site had already been written at the end of the baseline studies, requiring three years of monitoring.

\section{TIER 4: POST-CONSTRUCTION STUDIES TO ESTIMATE IMPACTS}

If potentially significant effects were predicted in Tiers 2 and 3, or there is uncertainty over their existence, Tier 4 consists of post-construction studies to evaluate those predictions and/or reduce the uncertainty regarding significance. Even if significant collision fatalities were not predicted, limited Tier 4 studies are ordinarily undertaken to confirm these predictions. These may include fatality studies and assessments of habitat loss, degradation, and fragmentation. The seven questions included in the Guidelines for Tier 4 are addressed here in order.

\section{Tier 4a. Fatality Studies}

Post-construction fatality monitoring consists of regular searches for bat or bird carcasses around turbines to quantify the number and distribution of fatalities by species. Fatality studies should be designed to respond to specific questions (USFWS 2012). The Guidelines state that post-construction fatality studies will be warranted for almost all facilities, at least for a year following construction. The exact duration of fatality studies, however, will vary according to the outcome of previous tiers, results compared to predictions, and Tier 4 monitoring results for comparable facilities and locations (i.e., topography, vegetation, species of concern). (See Table 2 in USFWS (2012) for recommendations on fatality monitoring durations and contingencies.) Fatality monitoring should be undertaken during all seasons that the species of concern is present (USFWS 2012). Selecting the number of turbines to monitor should be based on the variability in fatality rates among turbines from existing projects in the same region (Morrison et al. 2008, 
USFWS 2012).

Searches should be conducted using standard methods to facilitate comparisons between facilities and with predicted fatality rates (Strickland et al. 2011). Additional sources of information about fatality search protocols are found in references in Strickland et al. (2011) and USFWS (2012). Carcass removal rate is an important factor influencing the frequency of monitoring. For example, the higher carcass removal rate for small birds than for raptors suggests that monitoring for small birds should be more frequent (USFWS 2012). Results must be adjusted to account for removal of carcasses by scavengers, searcher carcass detection bias, and other potential sources of bias and error (Table 3). Two methods for correcting carcass numbers for these biases are presented in Huso (2011) and Shoenfeld (2004) and reviewed in Strickland et al. (2011). The relative accuracy of these estimators depends on the searcher efficiency, searcher efficiency trends over time, and ratio between average carcass removal time and search interval (Strickland et al. 2011). For example, estimators can be biased by the length of the search interval compared to the length of time a carcass is in a search plot (Strickland et al. 2011).

For Mount Storm, the West Virginia PSC required post-construction fatality monitoring of both birds and bats to be conducted for three months each spring and three months each fall for a total of three years (2009-2011), with an additional study being conducted in fall of 2008 after Phase 1 was operational. Because of this wording, a total of seven seasons of fatality studies were conducted, and post-construction monitoring is complete (Table 4).

\section{What are the bird and bat fatality rates for the project?}

Table 4 lists the estimated fatality rates that have been calculated in post-construction studies for Mount Storm Wind Energy Facility. The estimates of turbine-related fatality rates were based on four elements: 1) the observed number of fatalities, 2) searcher efficiency as determined by the proportion of planted carcasses observed by searchers, 3) carcass removal rates estimated as the length of time a planted carcass remained in the sampled area to be available for detection, and 4) the proportion of carcasses that likely fell in unsearched areas based on the distribution of observed carcasses and proportion of area searched around turbines (Young et al. 2009ab; 2010a,b; 2011a,b; 2012a). The estimated mean number of fatalities per turbine per study period was calculated for daily searches by dividing the mean fatality rate by an estimate of the probability a carcass was not removed and was detected and by adjusting for the area within the plot that was not searched (Erickson et al. 2003, Young et al. 2011a). 
Fatality estimates in Table 4 are expressed first as they were reported, then in standardized units. In reporting fatality rates, a standardized metric of fatalities per megawatt (MW) of nameplate capacity is recommended to facilitate comparison between turbines of different sizes (USFWS 2011). Each of Mount Storm Wind Energy Facility's current 132 turbines is rated at 2.0 MW nameplate capacity (Young et al. 2009a).

Over the three and a half years of post-construction monitoring, average fatalities per MW per 3-month study period have ranged from 0.35 to 3.90 for birds (Table 4). These values are in line with values for other wind energy facilities in the eastern United States.

The number of bat deaths has been substantially higher than avian fatalities, with averages ranging from 2.88 to 12.11 bat deaths per MW per 3-month study period (Young et al. 2009a, 2009b, 2010a, 2010b, 2011a, 2011b, 2012a) (Table 4). Bat fatality rates at Mount Storm Wind Power Project as a whole are in the top quartile of bat fatalities at other facilities that have been studied to date with publicly available results (Strickland et al 2011), particularly during fall study periods. This level of bat fatalities is similar to several other facilities in the northeastern U.S. (e.g., Maple Ridge, NY, and Casselman, PA), but much lower than those facilities in the top $10 \%$ (e.g., Mountaineer, WV and Buffalo Mountain, TN) located in mountainous areas in the eastern U.S.

\section{What are the fatality rates of species of concern?}

\section{Birds}

Observed collision fatality rates of many bird species of concern have been zero. These include bald eagle, northern goshawk, northern harrier, short-eared owl, northern sawwhet owl, Kirtland's warbler, golden-winged warbler, American woodcock, common snipe, and common nighthawk. The majority of fatalities were passerines.

\section{Bats}

Table 5 shows the portion of fatalities that represented the three migratory tree-bat species, hoary, silver-haired, and eastern red bats. In the seven study periods, these species comprised $56 \%$ to $92 \%$ of all bat fatalities. Post-construction fatality monitoring at Mount Storm has confirmed, as with other facilities studied, that these three species were killed in greater numbers than other bat species (Young et al. 2009a,b; 2010a,b; 2011a,b; 2012a).

Observed collision fatality rates of other species of concern have been zero. These include Indiana bat, Virginia big-eared bat, and Eastern small-footed bat. 


\section{How do the estimated fatality rates compare to the predicted fatality rates?}

\section{Birds}

Young et al. (2004) used the mortality rate of 2.37 bird deaths/turbine/fall season (the results of one season of post-construction monitoring at the nearby Mountaineer Wind Energy Center) to project fatality rates at Mount Storm prior to construction. The four fall seasons of post-construction monitoring which have now been completed at Mount Storm result in a higher estimated average mortality rate of 3.99 bird deaths/turbine/season. The spring average estimate (three study periods) is a slightly lower value, at 2.94 bird deaths/turbine/season. Bird fatality rates at Mount Storm are somewhat higher than estimates from the model used by Young et al. (2004).

Some fatalities represented birds that were not already on the list of species of concern, but none of these species are rare, and some may not have been killed by collision with turbines. These species include bay-breasted warbler, Bicknell's thrush, blackpoll warbler, cape may warbler, golden-crowned kinglet, gray-cheeked thrush, ruby-crowned kinglet, gray-cheeked thrush, cedar waxwing, Philadelphia vireo, sharp-shinned hawk, American robin, whippoorwill, American crow, European starling, field sparrow, ruffed grouse, turkey vulture, wild turkey, winter wren, and wood duck (this last species not on search plots) (Young et al. 2009a,b; 2010a,b; 2011a,b; 2012a).

\section{Bats}

The estimated number of bat fatalities at the Mountaineer Wind Energy Center during the fall of 2003 was 47.53 bats per turbine (Kerns and Kerlinger 2004). As stated above, this could be used as a preconstruction estimate for fatality rates at the Mount Storm Wind Energy Facility. However, post-construction estimates were lower, ranging from 9.10 to 24.21 bats per turbine in the fall and 5.77 to 9.98 in the spring (Table 5). Two Seminole bat (Lasiurus seminolus) casualties were identified at Mount Storm in fall 2010 (Young et al. 2011a), and this species was not identified as a species of concern because its range is typically further south, it prefers roost sites with Spanish moss, and only vagrants have been found in central West Virginia.

\section{Do bird and bat fatalities vary within the project site in relation to site characteristics?}


This question relates to spatial variability of fatalities (USFWS 2012), and we address this issue below. However, the Guidelines do not specifically mention environmental variables that vary temporally, such as low wind speed. We also address those variables here, because fatality reports at Mount Storm have found relationships between fatality rates for bats and wind speed.

Turbine-specific site characteristics such as distance from water sources, roosting sites, or forest edge have not been reported for the Mount Storm Wind Energy Facility, and so any correlations of these parameters with turbine-specific fatality rates is beyond the scope of this study. No specific turbine location was expected to reduce fatality rates over any other location on the project site (Young et al. 2004).

However, a close inspection of the existing post-construction mortality studies reveals that one turbine repeatedly produced higher bat mortality than any other turbine which was searched daily, at least in the first few seasons of post-construction study. Among turbines searched daily, turbine 81 had the highest fatalities of 9 turbines sampled in fall 2008, of 15 turbines in spring 2009, and of 15 turbines in fall 2009. It was in the $75^{\text {th }}$ percentile of fatalities for spring 2010, with the highest numbers of fatalities recorded at nearby turbine 83 . Turbine 81 was in the 91 st percentile of fatalities for fall 2010. In box-and-whiskers plots Turbine 81 was an extreme statistical outlier (i.e., using a criterion of 3 times the interquartile range) with respect to numbers of bat carcasses found at turbines searched daily for the first three seasons (Figure 3). During the fourth and fifth seasons, the numbers of bat fatalities were more typical for this turbine. No such difference was found in the numbers of bird carcasses found at each turbine. The turbine was not among those sampled in the sixth and seventh seasons.

Turbine 81 , near the northern tip of the site, is also the easternmost wind turbine at the Mount Storm Wind Energy Facility. Lacking more specific information on landscape features, however, one cannot determine which siting factors were causing bats to be preferentially attracted to or to preferentially collide with turbine 81 in the first year and a half of surveys. However, this turbine would be one of the first encountered when bats are flying south or west.

Bat fatalities were inversely correlated with wind speed variables (e.g., mean and median nightly wind speed, proportions of nights with wind speed $>6 \mathrm{~m} / \mathrm{sec}$ ) for all years (Young et al. 2009a, 2010a, 2011a, 2012a). Bat fatalities were also correlated with average nightly temperature and pressure.

\section{How do the fatality rates compare to the fatality rates from existing projects in similar landscapes with similar species composition and use?}


Three other wind energy facilities are located near the Mount Storm Wind Energy Facility, along the Allegheny Front. These are the Casselman Wind Project and the Meyersdale Wind Energy Center, both located in Somerset County, Pennsylvania, about 74 $\mathrm{km}$ north of Mount Storm, and Mountaineer Wind Energy Center, on Backbone Mountain, in Tucker County, West Virginia, about 27 km west of Mount Storm. Table 6 shows estimated bird fatalities per MW per yr, and Table 7 shows estimated bat fatalities per MW per study period at each of these facilities. Turbines differ in manufacturer; however all are between 70 and 80 meters in tower height, and rotor-swept areas are between 4072 and 5027 square meters. Estimated avian mortality rates at Mount Storm were consistent with, but somewhat higher than those at Casselman and Mountaineer (Table 6). Estimated mortality rates for bats are lower than those at nearby Casselman, Meyersdale, and Mountaineer (Table 7).

\section{What is the composition of fatalities in relation to migrating and resident birds and bats at the site?}

While determining residency is difficult, based on the species and timing of the fatalities, the majority of avian fatalities appeared to be migrant birds, especially passerines.

Similar to most other wind facilities in the U.S., the composition of bat fatalities has been heavily skewed toward the migratory tree-bat species (see question 2 in this tier). According to the West Virginia University Extension Service, the most common bat species in West Virginia are the little brown myotis, big brown bat (Eptesicus fuscus) and the eastern pipistrelle (Venable 1999). Presumably, these are the most common resident species. One might expect the most common bats to be the most commonly killed; however, none of these have been among the three species with the highest fatality rates at Mount Storm Wind Energy Facility, nor have they been the most common species killed at nearby facilities. The most prevalent fatalities at Mount Storm, the Mountaineer Wind Energy Center, the Casselman Wind Power Project (Arnett et al. 2009), and the Meyersdale Wind Energy Center have been hoary, silver-haired, and eastern red bats. The relatively higher fatality rates for migratory tree bats may reflect higher abundance during the migratory seasons or behavioral issues.

\section{Do fatality data suggest the need for measures to reduce impacts?}

Fatality rates at Mount Storm Wind Energy Facility are comparable to those at similar facilities in West Virginia and Pennsylvania, as described above. More research is needed to 
determine whether or not fatalities of migratory tree bats are at a level that is biologically significant. If impacts are biologically significant, mitigation measures would clearly be needed. But even if the impacts are not biologically significant, mitigation measures may be considered if they are inexpensive from an energy production and economic perspective but highly effective at reducing mortality. While there remains uncertainty because of lack of replication, this may be the case for curtailment during low wind speeds during seasons of bat migration, particularly where endangered species are at risk. This mitigation was effective at Mount Storm in trials in Young et al. (2011a).

\section{Tier 4b. Assessing Direct and Indirect Impacts of Habitat Loss, Degradation, and Fragmentation}

Tier 4b studies are conducted if Tier 3 studies show the presence of species of habitat fragmentation concern or if they indicate significant direct and indirect adverse impacts to species of concern (USFWS). These issues were not deemed significant in Tier 3, so no Tier $4 \mathrm{~b}$ studies were conducted.

\section{TIER 4 DECISION PROCESS AND OUTCOME}

Results of Tier 4 may support or refute Tier 3 predictions. The Tier 4 outcome should clearly describe significant adverse effects to individual wildlife and evaluate the potential impacts to populations, state which predictions were not realized, determine where the mitigation plan needs to be modified, and determine where other post-construction studies (Tier 5) are needed. An analysis of post-construction fatality data (Tier 4) for Mount Storm shows that avian fatality rates were close to predicted values, that some of the species affected were migratory birds, that fatalities of migratory tree bats were relatively higher than other species but close to values predicted for neighboring facilities, and that there was no observed take of endangered or threatened species.

\section{TIER 5: OTHER POST-CONSTRUCTION STUDIES}

Tier 5 studies can be conducted for one of three purposes, all of which are sitespecific: 1) to evaluate factors identified in Tier 4 that potentially led to adverse impacts such as collisions, 2) to determine why mitigation actions were ineffective, or 3 ) to evaluate 
demographic impacts on local populations of species of concern (USFWS 2012). It is anticipated that siting or mitigation measures for most wind energy projects will obviate the need for Tier 5 investigations. The three questions included in the Guidelines for Tier 5 are addressed here in order.

\section{To the extent that the observed fatalities exceed anticipated fatalities, are those} fatalities potentially having a significant adverse impact on local populations? Are observed direct and indirect impacts to habitat having a significant adverse impact on local populations?

Observed fatalities do not exceed anticipated fatalities. However, the uncertainty over the effects of the fatality rates for migratory tree bats at this and similar facilities suggests a population study may be warranted to determine whether the magnitude of fatalities might lead to measurable demographic impacts to local populations. Population studies are beyond the scope of individual projects and of this case study.

\section{Were mitigation measures implemented ... not effective? This includes habitat} mitigation measures as well as measures undertaken to reduce collision fatalities.

"Identifying, prioritizing, and testing hypothesized causes of bat collisions with wind turbines are vital steps toward developing practical solutions to the problem" (Cryan and Barclay 2009). Mitigation measures for bat collisions, such as the curtailment discussed in Tier 3 and tested in Arnett et al. (2011), were not implemented during the first several years of operation because there appeared to be little risk to endangered bats. Therefore, fatality rates for bats (until fall 2010 investigative studies, Young et al. 2011a) do not reflect mitigation measures. Even the state-of-the-art mitigation measures do not reflect causal relationships between environmental variables, bat behavior, and collision. The efficacy of other mitigation measures (e.g., lighting for birds, setbacks for West Virginia northern flying squirrel) was not tested.

\section{Are the estimated impacts of the proposed project likely to lead to population} declines in the species of concern (other than federally-listed species)?

Population viability analyses have not been undertaken for migratory tree bats that are comprise the majority of bat fatalities at many wind energy facilities. Moreover, the population status of these species is unknown. Therefore, whether declines of these species 
could result from the wind energy project, combined with other stressors, is uncertain. Population models would have to consider cumulative mortality, including collision fatalities from nearby wind energy facilities and (for bats) white-nose syndrome and habitat loss within the species range.

\section{DISCUSSION AND CONCLUSIONS}

The U.S. Fish and Wildlife Service developed "Land-based Wind Energy Guidelines" to provide a formal, voluntary system for assessing the effects of wind energy projects on species of concern (USFWS 2012). While formal, structured environmental assessments existed for impacts of some facilities on birds, all species of concern were not always identified, all potential types of effects (e.g., habitat fragmentation) were not always considered, and assessments were not always conducted in a way that facilitates early siting decisions early and later mitigation decisions. While approaches for assessing project site usage and collision risk to bats have recently been published (Kunz et al. 2007a, Strickland et al. 2011), the Guidelines illustrate how to embed those methods in a decision framework. This paper demonstrates the USFWS Guidelines at the Mount Storm Wind Power Project, Grant County, West Virginia, USA. This facility was selected because data were available for all tiers of the Guidelines. The objectives of this paper were 1) to apply the tiered assessment framework developed by USFWS to a case study, 2) to indicate how outputs of wildlife assessments previously undertaken for the case study site might have been different if a tiered assessment framework had been used, and 3) to assess benefits of a tiered ecological assessment framework for siting wind energy facilities. The purpose of this discussion is not to review the site-specific results described in the tiers above, but rather to perform a critical analysis of the tiered assessment Guidelines in the context of this case study.

This case study of the USFWS tiered assessment framework should be somewhat applicable to all wind energy facilities. The case study would be especially applicable to similar facilities in mountainous regions of the eastern US where collisions of turbines with bats and birds are the primary concerns. Because this case study lacked a habitat fragmentation analysis, this report is less applicable to facilities where displacement of grouse may be an issue, such as the grasslands of the Midwestern United States.

In general, the tiered structure of the Guidelines did not change conclusions compared to those of earlier environmental assessments conducted for the Mount Storm Wind Energy Facility. Bird fatalities and fatality estimates are similar to those of previous assessments. 
Estimates of the number and species composition of fatalities for bats contain more uncertainty than those of the more recent assessments at wind energy facilities; however, this difference is due to the knowledge that has been acquired in the past 10 years of environmental assessments for wind energy facilities and related research on bats. This assessment found risk to individual migratory tree-roosting bats (eastern red bats, silverhaired bats, hoary bats) that was not emphasized in previous preconstruction assessments. Moreover, we make the point that given the heightened concern about Indiana bats, due to white-nose syndrome and the current fatality record for this species, the tiered risk assessment would likely have recommended a more thorough evaluation of the site for the species, and perhaps consideration of mitigation measures for potential fatalities.

The case study highlighted some benefits of the tiered assessment framework in the USFWS Guidelines:

- Good communication among stakeholders. In the previous environmental assessments for Mount Storm, because of a lack of documentation, it was not always apparent that stakeholders and consultants doing different studies and assessments were talking to each other.

- Clear decision points. If the tiered assessment Guidelines had been in place, it may have been clearer why and when the southern phase of the Mount Storm project was abandoned.

- A standard assessment trajectory. The trajectory moves toward more detailed studies about a focused set of species of concern potentially impacted by a focused type of potential stressors at a focused location, with a defined mitigation. When Towner (2002a) of USFWS recommended many studies to support the environmental assessment of the Mount Storm Wind Energy Facility, the studies ranged from reconnaissance-level studies (e.g., conducting a survey for potential Cheat Mountain Salamander habitat on the project site) to more rigorous assessments (e.g., determining the amount of Indiana bat habitat remaining in the region following construction) to research studies (e.g., conducting a study to evaluate the effects of lights on bat feeding behavior). These recommended studies were of different types and rigor and would be organized accordingly in a tiered assessment.

- Narrowing the list of species of concern. The tiered assessment approach allowed the focus of rigorous studies to be on migratory tree bats and, to a lesser extent, passerines, rather than raptors or the West Virginia northern flying squirrel, for example.

- Encouraging standard study protocols. Because similar fatality estimation methods were used at other wind energy facilities in the region, it was possible to compare 
fatality results from Mount Storm to those of other wind plants to aid the developer in decision making.

- Promoting adaptive management through post-construction assessment and mitigation. Moderately high fatality results for bats, combined with new research on the benefits of turbine curtailment, led to a study of bat fatalities as affected by curtailment at Mount Storm.

With both a common assessment structure (USFWS 2012) and standard field protocols (Strickland et al. 2011, Kunz et al. 2007), numerous benefits will accrue to the assessment community when information is shared. The shared body of knowledge will include regional information (species of concern, habitat suitability maps, migratory pathways, fatality data from nearby facilities) and more general information (e.g., relationships between site use and fatality including species-specific behavior, potential mitigation actions). Already the rigor of this demonstration was increased by fatality data from the Mountaineer Wind Energy Center and results from increasing turbine cut-in speed at the Casselman Wind Project. Moreover, groups of tiered assessments conducted in a region can reduce the effort needed to conduct subsequent assessments in that region. If information on migratory corridors had already been available, it would have reduced the effort spent on the nocturnal migrant study, part of Tier 3 in this case study. In the future, early-tier studies and fatality studies will lead to a common understanding of regional species that need to be included (or may be excluded) as species of concern. Eventually, relative species susceptibilities to collision will be better understood, based on knowledge gained in and shared from post-construction assessments. Environmental factors correlated with fatalities are also being shared. For example, Kerns et al. (2005) found temporal correlations between total bat fatalities and fatalities of hoary and red bats at the Mountaineer Wind Energy Center in Tucker County, West Virginia, and the Meyersdale Wind Energy Center in Somerset County, Pennsylvania, that corresponded with weather variables such as wind speed, barometric pressure, and percent of the night that it rained.

The U.S. Fish and Wildlife Service "Land-based Wind Energy Guidelines" should help assessors develop well-organized, thorough, and cost-effective environmental assessments for wind energy that use standard decision points and field protocols. We hope that this demonstration will help wind energy developers and their contractors use these Guidelines. 


\section{ACKNOWLEDGMENTS}

We thank Yetta Jager and Manuela Huso for statistical advice. David Young provided site-specific knowledge. We thank Ellen Smith for reviewing an earlier version of this report. The Wind Turbine Guidelines Advisory Committee and USFWS are acknowledged for developing a useful tiered assessment approach. We thank Patrick Gilman for his guidance as project sponsor of this effort. This paper was developed as part of the project "A case study approach for determining benefits of ecological risk assessment frameworks for siting wind energy facilities," which was funded by the U.S, Department of Energy's Energy Efficiency and Renewable Energy Office. ORNL is managed by the UTBattelle, LLC, for DOE under contract DE-AC05-00OR22725. 


\section{REFERENCES}

Adam MD, Lacki MJ, Barnes TG (1994) Foraging areas and habitat use of the Virginia bigeared bat in Kentucky. Journal of Wildlife Management 58:462-469

Angus NB, P Clem, M Hamilton (2001a) Appalachian Corridor H Davis to Bismarck Project: mist net report for Myotis sodalis. West Virginia Department of Transportation

Angus NB, P Clem, M Hamilton (2001b) Appalachian Corridor H Bismarck to Forman Project: mist net report for Myotis sodalis. West Virginia Department of Transportation

Arnett EB, Brown WK, Erickson WP, Fiedler JK, Hamilton BL, Henry TH, Jain A, Johnson GD, Kerns J, Koford RR, Nicholson CP, O'Connell TJ, Piorkowski MD, Tankersley RD (2008) Patterns of bat fatalities at wind energy facilities in North America. Journal of Wildlife Management 72:61-78

Arnett EB, Schirmacher M, Huso MMP, Hayes JP (2009) Patterns of bat fatality at the Casselman Wind Project in south-central Pennsylvania. 2008 Annual Report. An annual report submitted to the Bats and Wind Energy Cooperative and the Pennsylvania Game Commission. Bat Conservation International. Austin, Texas, USA

Arnett EB, Huso MMP, Schirmacher MR, Hayes JP (2011) Altering turbine speed reduces bat mortality at wind-energy facilities. Frontiers in Ecology and the Environment 9:209-214

ASTM (1994) Emergency standard guide for risk-based corrective action applied to petroleum release sites. ES 38-94. American Society for Testing and Materials, Philadelphia, USA

Baerwald EF, Edworthy J, Holder M, Barclay RMR (2009) A large-scale mitigation experiment to reduce bat fatalities at wind energy facilities. Journal of Wildlife Management 73:1077-1081

Band W, Madders M, Whitfield DP (2006) Developing Field and Analytical Methods to Assess Avian Collision Risk at Wind Farms. In: Birds and Wind Power. de Lucas, M., G. Janss, and M. Ferrer, eds. Lynx Editions, Barcelona, Spain 
Bibby CJ, Burgess ND, Hill DA (1992) Bird Census Techniques. Academic Press, New York

BLM (1995a) Final KENETECH/PacifCorp Windpower Project Environmental Impact Statement. US Department of Interior, Bureau of Land Management, Rawlins District, DES95-2.

http://www.blm.gov/pgdata/etc/medialib/blm/wy/information/NEPA/rfodocs/footecreekwind.Par.91150.File.dat/FEIS.pdf

BLM (1995b) Draft KENETECH/PacifCorp Windpower Project Environmental Impact Statement. US Department of Interior, Bureau of Land Management, Rawlins District, DES95-2.

http://www.blm.gov/pgdata/etc/medialib/blm/wy/information/NEPA/rfodocs/footecreekwind.Par.71318.File.dat/DEISpt1.pdf

Brack V Jr., Stihler CW, Reynolds RJ, Butchkoski CM, Hobson CS (2002) Effect of climate and elevation on distribution and abundance in the mideastern United States. Pp 21-28 in The Indiana Bat: Biology and Management of an Endangered Species (A Kurta and J Kennedy, eds). Bat Conservation International, Austin, TX, USA

Bradshaw CR (2010) Effect of snake populations on salamanders as a result of forest fragmentation. Master's Thesis. Marshall University. Retrieved from http://proquest.umi.com/pqdlink?did=2095767511\&Fmt=7\&clientI $\mathrm{d}=79356 \& \mathrm{RQT}=309 \& \mathrm{VName}=\mathrm{PQD}$

Canterbury RA (2002) Phase I Avian Risk Assessment for a Proposed Wind Farm in Grant County, West Virginia. Prepared for Potesta \& Associates, Inc., Charleston, West Virginia, USA

Cryan PM (2008) Mating behavior as a possible cause of bat fatalities at wind turbines. Journal of Wildlife Management 72:845-49

Cryan PM, Barclay RMR (2009) Causes of bat fatalities at wind turbines: Hypotheses and predictions. Journal of Mammalogy 90:1330-1340

Dahl EL, Bevanger K, Nygard T, Roskaft E, Stokke BG (2012) Reduced breeding success in white-tailed eagles at Smola windfarm, western Norway, is caused by mortality and 
displacement. Biological Conservation 145:79-85

DOE (2008) 20\% Wind Energy by 2030. Increasing Wind Energy's Contribution to U.S. Electricity Supply. DOE/GO-102008-2567. U.S. Department of Energy, Washington, DC

DOI (1997) Record of Decision SeaWest/PacifiCorp Windpower Project. BLM/WY/PL97/018+5101. Prepared by Bureau of Land Management, Great Divide Resource Area, Rawlins District Office, Rawlins, WY

EPA (1998) Guidelines for Ecological Risk Assessment. EPA/630/R-95/002F. U.S. Environmental Protection Agency Risk Assessment Forum, Washington, D.C. http://www.epa.gov/raf/publications/pdfs/ECOTXTBX.PDF

Erickson WP, Gritski B, Kronner K (2003) Nine Canyon Wind Power Project Avian and Bat Monitoring Report, August 2003. Technical report submitted to Energy Northwest and the Nine Canyon Technical Advisory Committee

Erickson W, Johnson G, Young D, Strickland D, Good R, Bourassa M, Bay K, Sernka K (2002) Synthesis and Comparison of Baseline Avian and Bat Use, Raptor Nesting and Mortality Information from Proposed and Existing Wind Developments. Final. Prepared for Bonneville Power Administration, Portland, OR. WEST, Inc., Cheyenne, WY, December, 2002

Frick WF, Pollock JF, Hicks AC, Langwig KE, Reynolds DS, Turner GG, Butchkoski CM, Kunz TH (2010) An emerging disease causes regional population collapse of a common North American bat species. Science 329:679-682

Gardner JE, Cook EA (2002) Seasonal and geographic distribution and quantification of potential summer habitat. Pp. 9-20 in The Indiana bat: Biology and management of an endangered species (A Kurta and J Kennedy, eds), Bat Conservation International, Austin TX, USA

Garvin JC, Jennelle CS, Drake D, Grodsky SM (2011) Responses of raptors to a windfarm. Journal of Applied Ecology 48:199-209

Hall GA, Bell RK (1981) The diurnal migration of passerines along an Appalachian ridge. 
American Birds 35:135-138

Hall GA (1983) West Virginia Birds. Carnegie Museum of Natural History Special Publication No 7 Pittsburgh, PA, USA

Hill L (2010) Personal communication from Laura Hill, West Virginia Field Office of USFWS, to Robin Rice of Oak Ridge National Laboratory, October 8, 2010

Horn JW, Arnett EB, Kunz TH (2008) Behavioral responses of bats to operating wind turbines. Journal of Wildlife Management 72:123-32

Huchon JM, Clerman RJ, Wagner BO (1979) Tiered testing for chemical hazard assessment. Environmental Science \& Technology 13:1202-1207

Huso MMP (2011) An Estimator of wildlife fatality from observed carcasses. Environmetrics 22:318-329

Johnson GD, Erickson WP, Strickland MD, Shepherd MF, Shepherd DA (2000a) Avian Monitoring Studies at the Buffalo Ridge Wind Resource Area, Minnesota: Results of a 4Year Study. Final report prepared for Northern States Power Company, Minneapolis, Minnesota, by Western EcoSystems Technology (WEST), Inc., Cheyenne, Wyoming. September 22, 2000. 212 pp. http://www.west-inc.com

Johnson GD, Strickland MD (2003) Biological Assessment for the Federally Endangered Indiana Bat (Myotis sodalis) and Virginia Big-eared Bat (Corynorhinus townsendii virginianus) NedPower Mount Storm Wind Project, Grant County, West Virginia. Prepared For NedPower Mount Storm LLC, Chantilly, VA. Western Ecosystems Technology, Inc., Cheyenne, WY, USA

Johnson GD, Strickland MD (2004) An Assessment of Potential Collision Mortality of Migrating Indiana Bats (Myotis sodalis) and Virginia Big-eared Bats (Corynorhinus townsendii virginianus) Traversing Between Caves. Supplement to: Biological Assessment for the Federally Endangered Indiana Bat (Myotis sodalis) and Virginia Big-eared Bat (Corynorhinus townsendii virginianus) NedPower Mount Storm Wind Project, Grant County, West Virginia. Prepared for NedPower Mount Storm LLC, Chantilly, VA. Western Ecosystems Technology, Inc., Cheyenne, WY, USA 
Jordan MA, Morris DA, Gibson SE (2009) The influence of historical landscape change on genetic variation and population structure of a terrestrial salamander (Plethodon cinereus). Conservation Genetics 10:1647-1658

Kerlinger P (1995) How birds migrate. Stackpole Books, Mechanicsburg, PA, USA

Kerns J, Kerlinger P (2004) A Study of Bird and Bat Collision Fatalities at the Mountaineer Wind Energy Center, Tucker County, West Virginia: Annual Report for 2003. Prepared for FPL Energy and the Mountaineer Wind Energy Center Technical Review Committee.

Prepared by Curry and Kerlinger, LLC, and Center for Environmental Science, Appalachian Laboratory, UMCES, Frostburg, MD. February 14, 2004

Kerns J, Erickson WP, Arnett EB (2005) Bat and bird fatality at wind energy facilities in Pennsylvania and West Virginia. pp. 24-95 in EB Arnett, technical editor. Relationships between Bats and Wind Turbines in Pennsylvania and West Virginia: An Assessment of Fatality Search Protocols, Patterns of Fatality, and Behavioral Interactions with Wind Turbines. A final report submitted to the Bats and Wind Energy Cooperative. Bat Conservation International, Austin, TX, USA

Kunz T, Arnett E, Cooper B, Erickson W, Larkin R, Mabee T, Morrison M, Strickland M, Szewczak J (2007a) Assessing Impacts of Wind-Energy Development of Nocturnally Active Birds and Bats: A Guidance Document. Journal of Wildlife Management 71:2449-2486

Kunz TH, Arnett EB, Erickson WP, Hoar AR, Johnson GD, Larkin RP, Strickland MD, Thresher RW, Tuttle MD (2007) Ecological impacts of wind energy development on bats: questions, research needs, and hypotheses. Frontiers in Ecology and Environment 5:315-324

Mabee TJ, Cooper BA, Plissner JH (2004) A Radar Study of Nocturnal Bird Migration at the Proposed Mount Storm Wind Power Development, West Virginia, Fall 2003, Final Report. Prepared for Western Ecosystems Technology, Inc., Cheyenne, Wyoming and NedPower US LLC., Chantilly, Virginia. Prepared by ABR, Inc. Environmental Research \& Services, Forest Grove, Oregon, USA, March 2004

Mabee T, Cooper B, Plissner J, Young D (2006) Nocturnal Bird Migration over an Appalachian Proposed Wind Power Project. Wildlife Society Bulletin 34:682-690 
Manville AM, II (2009) Towers, Turbines, Power Lines, and Buildings - Steps Being Taken by the U.S. Fish and Wildlife Service to Avoid or Minimize Take at These Structures. In: Rich TD., Arizmendi C, Demarest D, Thompson C (eds.). Proceedings 4th International Partners in Flight Conference: Tundra to Tropics. McAllen, Texas. Pp. 262-272.

McCoy LE (2002) Public Service Commission of West Virginia, Charleston. Case No. 021189-E-CN, NedPower Mount Storm, LLC. Direct Testimony of Laidley E. McCoy. October 17, 2002

Michael ED (2002a) Surveys for Potential Habitat of the West Virginia Northern Flying Squirrel at Proposed NedPower, Mount Storm LLC Windmill Turbines Project Site. Prepared for NedPower Mount Storm LLC/Potesta \& Associates. August 19, 2002

Michael ED (2002b) West Virginia Northern Flying Squirrel Surveys at Three Sites Within the Proposed NedPower Mount Storm LLC Windmill Turbines Project Area, Grant County, West Virginia. Prepared for NedPower Mount Storm LLC/Potesta \& Associates. November 6,2002

Morrison ML, Block WM, Strickland MD, Collier BA, Peterson MJ (2008) Wildlife Study Design. Second Edition. Springer, New York, New York, USA. 358 pp.

Murray JJ (2002) Wind Turbines in West Virginia, An Independent Review of Reports and Opinions. Prepared for the Friends of the Allegheny Front. October 30, 2002. (Exhibit 1 in Public Service Commission of West Virginia, Charleston. Case No. 02-1189-E-CN, NedPower Mount Storm, LLC. Testimony of Linda Cooper, October 31, 2002, pp. 28-34

NedPower Mount Storm LLC (2002) Application for Certificate of Convenience and Necessity to Authorize Construction and Operation of a Wholesale Windpower Electric Generating Facility and Related Interconnection Facilities in Grant County, West Virginia. Submitted to the Public Service Commission of West Virginia on August 8, 2002

Niessen H (2002) Public Service Commission of West Virginia, Charleston. Case No. 021189-E-CN, NedPower Mount Storm, LLC. Direct Testimony of Hieronymus (Jerome) Niessen. October 17, 2002. 
NRC (2007) Environmental Impacts of Wind-Energy Projects. National Research Council. National Academies Press. Washington, D.C., USA. www.nap.edu

Owen SF, Menzel MA, Ford WM, Chapman BR, Miller KV, Edwards JW, Wood PB (2001) First summer record of a female Indiana bat, Myotis sodalis, in West Virginia. Journal of the Elisha Mitchell Scientific Society 117:132-134

Pauley TK (2002) Habitat Assessments for Potential Habitat of Cheat Mountain Salamanders (Plethodon nettingi) in Proposed Windmill Sites of the NedPower Mount Storm LLC. Prepared for Potesta \& Associates, Inc., Charleston, West Virginia, September 6, 2002

Pauley TK, Watson MB (2002) Inventories for Cheat Mountain Salamanders (Plethodon nettingi) near Stack Rock in a Proposed Windmill Site by NedPower Mount Storm LLC. Prepared for Potesta \& Associates, Inc., Charleston, West Virginia. October 28, 2002

Pearce-Higgins JW, Stephen L, Langston RHW, Bainbridge IP, Bullman R (2009) The distribution of breeding birds around upland wind farms. Journal of Applied Ecology 46:1323-1331.

Podolsky R (2004) Application of Risk Assessment Tools: Avian Risk of Collision Model. (Schwartz SS, ed.) Pp. 186-187. In: Proceedings Onshore Wildlife Interactions with Wind Developments: Research Meeting V. Lansdowne, Virginia. November 3-4, 2004. Prepared for the Wildlife Subcommittee of the National Wind Coordinating Collaborative (NWCC) by RESOLVE, Inc., Washington DC, 120 pp.

PSCWV (2003) Final Commission Order Authorizing NedPower to Construct and Operate a Wholesale Windpower Electric Generating Facility and Related Interconnection Transmission Facilities in Grant County, Subject to Certain Conditions. April 2, 2003. Case number 02-1189-E-CN, Public Service Commission of West Virginia

Reynolds RT, Scott JM, Nussbaum RA (1980) A variable circular-plot method for estimating bird numbers. Condor 82:309-313

Robbins CS (2002) Comments on Proposals for Windpower Facilities on Allegheny Ridges. Prepared for the Maryland Public Service Commission in regard to the Allegheny Heights Windpower Facility case \#8938. October 8, 2002. (Exhibit 2 in Ockene and Glitzenstein, 60 
Day Notice of Violations of the Endangered Species Act in Connection With the West Virginia Northern Flying Squirrel. February 3, 2003

Sargent B (2002) Letter to J Yeager, Potesta \& Associates, Inc., August 2, 2002 from West Virginia Division of Natural Resources, Wildlife Resources Section

Shoenfeld P (2004) Suggestions regarding avian mortality extrapolation. Technical memo provided to FPL Energy. West Virginia Highlands Conservancy, HC70, Box 553, Davis, West Virginia, 26260

Sparks JL, Jr. (2008) Genetic Variability, Pathogen Susceptibility, Subspecies Identity and Conservation of the Endangered Northern Flying Squirrel (Glaucomys sabrinus) in Virginia. Master's Thesis, Virginia Commonwealth University, Retrieved from http://hdl.handle.net/10156/2050

Stihler CW, Brack V, Jr. (1992) A survey of hibernating bats in Hellhole Cave, Pendleton County, West Virginia. Proceedings of the West Virginia Academy of Science 64:97-103

Strickland MD, Arnett E, Erickson WP, Johnson DH, Johnson GD, Morrison ML, Schaffer JA, Warren-Hicks W (2011) Comprehensive Guide to Studying Wind Energy/Wildlife Interactions. Prepared for the National Wind Coordinating Collaborative, Washington, DC, USA. http://www.nationalwind.org/assets/publications/Comprehensive_Guide_to_Studying_Wind Energy_Wildlife_Interactions_2011_Updated.pdf

Towner JK (2002a) Letter to J Yeager, Potesta \& Associates, Inc., August 30, 2002. From Field Supervisor, United States Department of the Interior Fish and Wildlife Service, West Virginia Field Office, Exhibit 6 of Public Service Commission of West Virginia, Charleston. Case No. 02-1189-E-CN, NedPower Mount Storm, LLC. Testimony of Linda Cooper, October 31, 2002, pp. 88-94

Towner JK (2002b) Letter to Mr. Tim Heinle, NedPower Mount Storm, LLC. December 3, 2002. United States Department of the Interior, Fish and Wildlife Service, West Virginia Field Office

Tucker VA (1996) A Mathematical Model of Bird Collisions with Wind Turbine Rotors. 
Transcripts of the ASME Journal of Solar Energy Engineering 118: 253-262

USFWS (2001) Appalachian Northern Flying Squirrels (Glaucomys sabrinus fuscus) (Glaucomys sabrinus coloratus) Recovery Plan Update. Amendment to Appendix A. Appalachian Northern Flying Squirrels Recovery Plan (1990). Guidelines For Habitat Identification and Management For Glaucomys sabrinus fuscus. United States Fish and Wildlife Service West Virginia Field Office, Elkins, WV, September 6, 2001

USFWS (2011) Endangered and threatened wildlife and plants; 90-day finding on a petition to list the eastern small-footed bat and the Northern long-eared bat as threatened or endangered. 76 FR 38095. https://www.federalregister.gov/articles/2011/06/29/201116344/endangered-and-threatened-wildlife-and-plants-90-day-finding-on-a-petition-to-listthe-eastern\#p-3

USFWS (2012) U.S. Fish and Wildlife Service Land-Based Wind Energy Guidelines. http://www.fws.gov/windenergy/docs/WEG_final.pdf. U.S. Fish and Wildlife Service, Arlington, VA, USA

Venable N (1999) Wildlife: Bats. Retrieved from the West Virginia University Extension Service website: http://www.wvu.edu/ agexten/wildlife/bats.pdf

Weller TJ, Baldwin JA (2012) Using echolocation monitoring to model bat occupancy and inform mitigations at wind energy facilities. Journal of Wildlife Management 76:619-631

The Wildlife Society (2007) Impacts of Wind Energy Facilities on Wildlife and Wildlife Habitat. Bethesda, MD, USA

Young D, M Lout, Z Courage, S Nomani, K Bay (2012b) 2011 Post-Construction Monitoring Study. Criterion Wind Project, Garrett County, Maryland. April 2011-November 2011. Prepared for Criterion Power Partners, LLC, Oakland, MD. Western EcoSystemsTechnology, Inc., Cheyenne, Wyoming \& Waterbury, VT. April 20, 2012

Young DP, Strickland D, Erickson W, Bay K, Canterbury R (2003) Spring Migration Avian Studies for the Proposed Mount Storm Wind Power Project, Grant County, West Virginia, May - July 2003. Prepared for NedPower Mount Storm, Chantilly, VA. Western EcoSystemsTechnology, Inc., Cheyenne, Wyoming, USA 
Young DP, Strickland D, Erickson W, Bay K, Canterbury R, Mabee T, Cooper B, Plissner J (2004) Baseline Avian Studies: Mount Storm Wind Power Project, Grant County, West Virginia. Final Report, April 2004. Prepared for NedPower Mount Storm, Chantilly, VA, USA

Young DP, Erickson WP, Bay K, Nomani S, Tidhar W (2009a) Mount Storm Wind Energy Facility, Phase 1 Post-Construction Avian and Bat Monitoring, July-October 2008. Prepared for NedPower Mount Storm, LLC, Houston, Texas, Western EcoSystems Technology, Inc., Cheyenne, Wyoming. February 17, 2009

Young DP Jr., Nomani S, Courage Z, Bay K (2011b) NedPower Mount Storm Wind Energy Facility Post-Construction Avian and Bat Monitoring. April-July 2011. Prepared for NedPower Mount Storm, LLC, Houston, Texas. Western EcoSystems Technology, Inc., Cheyenne, Wyoming

Young DP Jr., Nomani S, Courage Z, Bay K (2012a) NedPower Mount Storm Wind Energy Facility Post-Construction Avian and Bat Monitoring. July-October 2011. Prepared for NedPower Mount Storm, LLC, Houston, Texas. Western EcoSystems Technology, Inc., Cheyenne, Wyoming

Young DP, Bay K, Nomani S, Tidhar WL (2009b) NedPower Mount Storm Wind Energy Facility Post-Construction Avian and Bat Monitoring, March-June 2009. Prepared for: NedPower Mount Storm, LLC. Western Ecosystems Technology, Inc., Cheyenne, Wyoming. August 17, 2009

Young DP, Bay K, Nomani S, Tidhar WL (2010a) NedPower Mount Storm Wind Energy Facility Post-Construction Avian and Bat Monitoring, July-October 2009. Prepared for: NedPower Mount Storm, LLC, Houston, TX. Western Ecosystems Technology, Inc., Cheyenne, Wyoming. February 12, 2010

Young DP, Bay K, Nomani S, Tidhar WL (2010b) NedPower Mount Storm Wind Energy Facility Post-Construction Avian and Bat Monitoring, April-July, 2010. Prepared for NedPower Mount Storm, LLC, Houston, TX. Western Ecosystems Technology, Inc., Cheyenne, Wyoming. August 27, 2010 
Young DP, Nomani S, Tidhar WL, Bay K (2011a) NedPower Mount Storm Wind Energy Facility Post-Construction Avian and Bat Monitoring, July-October 2010. Prepared for NedPower Mount Storm, LLC, Houston, TX. Western Ecosystems Technology, Inc., Cheyenne, Wyoming. February 10, 2011

Youngbaer P (2011) Hellhole Cave, West Virginia: WNS photo-documentation trip and bat survey, February 20, 2010. NSS News. April 2011 
Table 1. Species of concern at the Mount Storm Wind Energy Facility

\begin{tabular}{|c|c|c|}
\hline Animal Species of Concern: & Status & Reference: \\
\hline Acadian flycatcher (Empidonax virescens) & MB & Young, et al, 2004 \\
\hline Allegheny woodrat (Neotoma magister) & S3, G3,G4 & Sargent, 2002 \\
\hline American redstart (Setophaga ruticilla) & MB & $\begin{array}{l}\text { Canterbury, 2002; Young, et al, 2004; Kerns and } \\
\text { Kerlinger, 2004 }\end{array}$ \\
\hline American woodcock (Scolouax minor) & none & Towner, 2002b; Canterbury, 2002; Young, et al, 2004 \\
\hline Bald eagle (Haliueetus Leucocephalus) & $\mathrm{S} 2 \mathrm{~B}, \mathrm{~S} 3 \mathrm{~N}, \mathrm{G}$ & Sargent, 2002; Towner, 2002a; Young, et al, 2004 \\
\hline Baltimore oriole (Icterus galbula) & MB & Canterbury, 2002; Young, et al, 2004 \\
\hline Barn swallow (Hirundo rustica) & MB & Canterbury, 2002; Young, et al, 2004 \\
\hline Belted kingfisher (Megaceryle alcyon) & MB & Canterbury, 2002; Young, et al, 2004 \\
\hline Big brown bat & & Kerns and Kerlinger, $2004^{1}$ \\
\hline Black-and-white warbler (Mniotilta varia) & MB & Canterbury, 2002; Young, et al, 2004 \\
\hline Black-billed cuckoo (Coccyzus erythropthalmus) & MB & $\begin{array}{l}\text { Canterbury, 2002; Young, et al, 2004; Kerns and } \\
\text { Kerlinger, } 2004^{1}\end{array}$ \\
\hline Black-throated blue warbler (Dendroica caerulescens) & MB & Canterbury, 2002; Young, et al, 2004 \\
\hline Black-throated green warbler (Dendroica virens) & MB & Canterbury, 2002; Young, et al, 2004 \\
\hline Blackburnian warbler (Dendroica fusca) & $\mathrm{MB}, \mathrm{S} 3 \mathrm{~B}, \mathrm{G}$ & Young, et al, 2004 \\
\hline Blue grosbeak (Passerina caerulea) & MB & Canterbury, 2002 \\
\hline Blue-gray gnatcatcher (Polioptila caerulea) & MB & Canterbury, 2002; Young, et al, 2004 \\
\hline Blue-winged warbler (Vermivora pinus) & $\mathrm{MB}$ & Young, et al, 2004 \\
\hline Blueheaded vireo (Vireo solitarius) & MB & Young, et al, 2004 \\
\hline Bobolink (Dolichonyx oryzivorus) & $\mathrm{MB}, \mathrm{S} 3 \mathrm{~B}, \mathrm{G}$ & Canterbury, 2002; Young, et al, 2004 \\
\hline Broad-winged hawk (Buteo platypterus) & MB & Canterbury, 2002; Young, et al, 2004 \\
\hline Canada warbler (Wilsonia canadensis) & MB & $\begin{array}{l}\text { Canterbury, 2002; Young, et al, 2004; Kerns and } \\
\text { Kerlinger, } 2004^{1}\end{array}$ \\
\hline Cerulean warbler (Dendroica cerulea) & MB & Young, et al, 2004 \\
\hline Cheat mountain salamander (Plethodon nettingi) & S2, G2, LT & Sargent, 2002; Towner, 2002a; Pauley, 2002 \\
\hline Chestnut-sided warbler (Dendroica pensylvanica) & MB & $\begin{array}{l}\text { Canterbury, 2002; Young, et al, 2004; Kerns and } \\
\text { Kerlinger, 2004 }\end{array}$ \\
\hline Chimney swift (Chaetura pelagica) & $\mathrm{MB}$ & Young, et al, 2004 \\
\hline Chipping sparrow (Spizella passerina) & $\mathrm{MB}$ & Canterbury, 2002; Young, et al, 2004 \\
\hline Cliff swallow (Petrochelidon pyrrhonota) & MB & Canterbury, 2002; Young, et al, 2004 \\
\hline Common nighthawk (Chordeiles minor) & MB & Young, et al, 2004 \\
\hline Common snipe (Gallinago gallinago) & none & Towner, 2002b; Young, et al, 2004 \\
\hline Common yellowthroat (Geothlypis trichas) & MB & $\begin{array}{l}\text { Canterbury, 2002; Young, et al, 2004; Kerns and } \\
\text { Kerlinger, 2004 }\end{array}$ \\
\hline Eastern kingbird (Tyrannus tyrannus) & MB & Canterbury, 2002; Young, et al, 2004 \\
\hline Eastern phoebe (Sayornis phoebe) & MB & Canterbury, 2002; Young, et al, 2004 \\
\hline Eastern pipistrelle (tricolored bat, Perimyotis subflavus) & & Kerns and Kerlinger, $2004^{1}$ \\
\hline Eastern small-footed bat (Myotis leibii) & S1, G3 & Sargent, 2002 \\
\hline Eastern wood-pewee (Contopus virens) & MB & Canterbury, 2002; Young, et al, 2004 \\
\hline Golden-winged warbler (Vermivora chrysoptera) & $\mathrm{MB}, \mathrm{S} 2 \mathrm{~B}, \mathrm{G}$ & Canterbury, 2002; Young, et al, 2004 \\
\hline Grasshopper sparrow (Ammodramus savannarum) & $\mathrm{MB}, \mathrm{S} 3 \mathrm{~B}, \mathrm{G}$ & Canterbury, 2002; Young, et al, 2004 \\
\hline Gray catbird (Dumetella carolinensis) & MB & Canterbury, 2002; Young, et al, 2004 \\
\hline Great-crested flycatcher (Myiarchus crinitus) & MB & Canterbury, 2002 \\
\hline Hermit thrush (Catharus guttatus) & MB & Canterbury, 2002; Young, et al, 2004 \\
\hline Hoary bat (Lasiurus cinereus) & none & $\begin{array}{l}\text { Erickson et al., 2002; Towner, 2002a; Johnson \& } \\
\text { Strickland, 2004; Kerns and Kerlinger, } 2004^{1}\end{array}$ \\
\hline Hooded warbler (Wilsonia citrina) & MB & $\begin{array}{l}\text { Canterbury, 2002; Young, et al, 2004; Kerns and } \\
\text { Kerlinger, 2004 }\end{array}$ \\
\hline House wren (Troglodytes aedon) & MB & Young, et al, 2004 \\
\hline Indiana bat (Myotis sodalis) & S1, G2, LE & Towner, $2002 \mathrm{a}$ \\
\hline Indigo bunting (Cyanocompsa parellina) & MB & $\begin{array}{l}\text { Canterbury, 2002; Young, et al, 2004; Kerns and } \\
\text { Kerlinger, } 2004^{1}\end{array}$ \\
\hline Kentucky warbler (Oporornis formosus) & MB & Young, et al, 2004 \\
\hline Kirtland's warbler (Dendroica kirtlandii) & LE & Murray, 2002; Robbins, 2002 \\
\hline
\end{tabular}




\begin{tabular}{|c|c|c|}
\hline Animal Species of Concern: & Status & Reference: \\
\hline Lark sparrow (Chondestes grammacus) & $\mathrm{MB}, \mathrm{S} 1 \mathrm{~B}, \mathrm{G}$ & Young, et al, 2004 \\
\hline Least flycatcher (Empidonax minimus) & MB & Canterbury, 2002; Young, et al, 2004 \\
\hline Lincoln's sparrow (Melospiza lincolnii) & MB & Young, et al, 2004 \\
\hline Little brown bat (Myotis lucifugus) & & Kerns and Kerlinger, $2004^{1}$ \\
\hline Louisiana waterthrush (Seiurus motacilla) & MB & Canterbury, 2002 \\
\hline Magnolia warbler (Dendroica magnolia) & MB & $\begin{array}{l}\text { Canterbury, 2002; Young, et al, 2004; Kerns and } \\
\text { Kerlinger, } 2004^{1}\end{array}$ \\
\hline Mourning warbler (Oporornis philadelphia) & MB & Young, et al, 2004 \\
\hline Nashville warbler (Vermivora ruficapilla) & $\mathrm{MB}, \mathrm{S} 1 \mathrm{~B}, \mathrm{G}$ & Young, et al, 2004 \\
\hline Northern goshawk (Accipiter gentilis) & S1, G5 & Towner, 2002a; Young, et al, 2004 \\
\hline Northern harrier (Circus cyaneus) & S1B, S3N, & Towner, 2002a. Canterbury, 2002 \\
\hline Northern long-eared bat (Myotis septentrionalis) & & Kerns and Kerlinger, $2004^{1}$ \\
\hline Northern parula (Parula americana) & MB & Canterbury, 2002; Young, et al, 2004 \\
\hline $\begin{array}{l}\text { Northern rough-winged swallow (Stelgidopteryx } \\
\text { serripennis) }\end{array}$ & MB & Canterbury, 2002; Young, et al, 2004 \\
\hline Northern saw-whet owl (Aegolius acadicus) & S1N, S2B, & Towner, 2002a; Young, et al, 2004 \\
\hline Northern waterthrush (Seiurus noveboracensis) & $\mathrm{MB}, \mathrm{S} 2 \mathrm{~B}, \mathrm{G}$ & Canterbury, 2002 \\
\hline Orchard oriole (Icterus spurius) & $\mathrm{MB}$ & Canterbury, 2002 \\
\hline Osprey (Pandion haliaetus) & $\mathrm{MB}, \mathrm{S} 2 \mathrm{~B}, \mathrm{G}$ & Canterbury, 2002; Young, et al, 2004 \\
\hline Ovenbird (Seiurus aurocapilla) & MB & Canterbury, 2002; Young, et al, 2004 \\
\hline Peregrine falcon (Falco peregrinus) & $\mathrm{MB}, \mathrm{S} 1 \mathrm{~B}, \mathrm{~S}$ & Young, et al, 2004 \\
\hline Pine warbler (Dendroica pinus) & MB & Young, et al, 2004 \\
\hline Pink-edged sulphur butterfly (Colias interior) & S1, G5 & Sargent, 2002 \\
\hline Prairie warbler (Dendroica discolor) & MB & Canterbury, 2002 \\
\hline Red bat (Lasiurus borealis) & none & $\begin{array}{l}\text { Erickson et al, 2002; Towner, 2002a; Johnson \& } \\
\text { Strickland, 2004; Kerns and Kerlinger, } 2004^{1}\end{array}$ \\
\hline Red-eyed vireo (Vireo olivaceus) & MB & $\begin{array}{l}\text { Canterbury, 2002; Young, et al, 2004; Kerns and } \\
\text { Kerlinger, 2004 }\end{array}$ \\
\hline Red-tailed hawk (Buteo jamaicensis) & & Kerns and Kerlinger, $2004^{1}$ \\
\hline Rose-breasted grosbeak (Pheucticus ludovicianus) & $\mathrm{MB}$ & $\begin{array}{l}\text { Canterbury, 2002; Young, et al, 2004; Kerns and } \\
\text { Kerlinger, 2004 }\end{array}$ \\
\hline Ruby-throated hummingbird (Archilochus colubris) & MB & Canterbury, 2002; Young, et al, 2004 \\
\hline Savannah sparrow (Passerculus sandwichensis) & MB & Canterbury, 2002; Young, et al, 2004 \\
\hline Scarlet tanager (Piranga olivacea) & MB & Canterbury, 2002; Young, et al, 2004 \\
\hline Short-eared owl (Asio flammeus) & S1, G5 & Towner, 2002a \\
\hline Silver-haired bat (Lasionycteris noctivagans) & S2, G5 & $\begin{array}{l}\text { Erickson et al, 2002; Johnson \& Strickland, 2004; } \\
\text { Kerns and Kerlinger, 2004 }\end{array}$ \\
\hline Sora (Porzana carolina) & $\mathrm{MB}, \mathrm{S} 1 \mathrm{~B}, \mathrm{~S}$ & Young, et al, 2004 \\
\hline Swainson's thrush (Catharus ustulatus) & $\mathrm{MB}, \mathrm{S} 3 \mathrm{~B}, \mathrm{G}$ & Young, et al, 2004 \\
\hline Timber rattlesnake (Crotalus horridus) & S3, G4 & Sargent, 2002 \\
\hline Tree swallow (Tachycineta bicolor) & MB & Canterbury, 2002; Young, et al, 2004 \\
\hline Veery (Catharus fuscescens) & MB & $\begin{array}{l}\text { Canterbury, 2002; Young, et al, 2004; Kerns and } \\
\text { Kerlinger, 2004 }{ }^{1}\end{array}$ \\
\hline $\begin{array}{l}\text { Virginia big-eared bat (Corynorhinus townsendii } \\
\text { virginianus) }\end{array}$ & S2, G4, LE & Sargent, 2002; Towner, 2002a \\
\hline $\begin{array}{l}\text { West Virginia northern flying squirrel (Glaucomys } \\
\text { sabrinus fuscus) }\end{array}$ & $\begin{array}{l}\text { S2, G5, } \\
\text { LE* }\end{array}$ & Sargent, 2002; Towner, 2002a; Michael, 2002a \\
\hline White-eyed vireo (Vireo griseus) & MB & Canterbury, 2002; Young, et al, 2004 \\
\hline Wood thrush (Hylocichla mustelina) & MB & $\begin{array}{l}\text { Canterbury, 2002; Young, et al, 2004; Kerns and } \\
\text { Kerlinger, 2004 }\end{array}$ \\
\hline Worm-eating warbler (Helmitheros vermivorus) & $\mathrm{MB}$ & Canterbury, 2002; Young, et al, 2004 \\
\hline Yellow warbler (Dendroica petechia) & MB & Canterbury, 2002; Young, et al, 2004 \\
\hline Yellow-bellied flycatcher (Empidonax flaviventris) & MB,S1B,G & Young, et al, 2004 \\
\hline Yellow-bellied sapsucker (Sphyrapicus varius) & $\mathrm{MB}, \mathrm{S} 1 \mathrm{~B}, \mathrm{~S}$ & Canterbury, 2002; Young, et al, 2004 \\
\hline Yellow-billed cuckoo (Coccyzus americanus) & MB & Young, et al, 2004; Kerns and Kerlinger, $2004^{1}$ \\
\hline Yellow-breasted chat (Icteria virens) & MB & Canterbury, 2002; Young, et al, 2004 \\
\hline Yellow-rumped warbler (Dendroica coronata) & $\mathrm{MB}$ & Young, et al, 2004 \\
\hline Yellow-throated vireo (Dendroica dominica) & MB & Canterbury, 2002; Young, et al, 2004 \\
\hline
\end{tabular}




\begin{tabular}{|l|l|l|}
\hline Animal Species of Concern: & Status & Reference: \\
\hline Yellow-throated warbler (Dendroica dominica) & MB & Young, et al, 2004 \\
\hline Plant Species of Concern: & & \\
\hline Balsam fir (Abies bulsamea) & S3, G5 & Sargent, 2002 \\
\hline Goldthread (Coptis trifolia ssp. Groenlundica) & S3, G5 & Sargent, 2002 \\
\hline Hoary sedge (Carex canescens) & S3, G5 & Sargent, 2002 \\
\hline Small cranberry (Vaccinium oxycoccos) & S3, G5 & Sargent, 2002 \\
\hline Star violet (Dalibarda repens) & S3, G5 & Sargent, 2002 \\
\hline Sundew (Drosera rotundifolia) & S3, G5 & Sargent, 2002 \\
\hline
\end{tabular}

Status Listings from West Virginia Division of Natural Resources, Wildlife Resources Section,

(http://www.wvdnr.gov/wildlife/rareSpecList.shtm).

${ }^{1}$ Reference is for fatality report for Mountaineer Wind Energy facility, species not necessarily observed at Mount Storm

* Species determined not to be present in Tier 3 study.

Key:

B Breeding populations

G2 Very rare and imperiled. 6-20 individuals remaining globally.

G3 Very rare and local, or found only in restricted range. 21-100 individuals remaining globally.

G4 Common and apparently secure globally.

G5 Very common and demonstrably secure globally.

LE Federally listed as endangered.

LE* The WV northern flying squirrel was removed from endangered status on August 26, 2008.

LT Federally listed as threatened.

MB Protected by the Migratory Bird Treaty Act

N Nonbreeding populations

S1 Extremely rare and critically imperiled. 1-5 individuals remaining within West Virginia.

S2 Very rare and imperiled. 6-20 individuals remaining within West Virginia.

S3 21-100 individuals remaining within West Virginia. 
Table 2. Tier 3 wildlife studies at the proposed Mount Storm Project site.

\begin{tabular}{|c|c|c|c|}
\hline Study & Objectives & Results & Reference \\
\hline $\begin{array}{l}\text { West Virginia } \\
\text { Northern Flying } \\
\text { Squirrel Survey }\end{array}$ & $\begin{array}{l}\text { - Determine whether the } \\
\text { squirrel is present } \\
\text { - Map suitable habitat for the } \\
\text { squirrel }\end{array}$ & $\begin{array}{l}\text { Six squirrels were trapped, } \\
\text { indicating that this endangered } \\
\text { species was present. All suitable } \\
\text { habitat for the species within the } \\
\text { potential project site was mapped. } \\
\text { A } 150 \text { foot construction buffer zone } \\
\text { was created around all mapped } \\
\text { habitat. }\end{array}$ & Michael, 2002b \\
\hline $\begin{array}{l}\text { Cheat Mountain } \\
\text { Salamander } \\
\text { Survey }\end{array}$ & $\begin{array}{l}\text { Determine whether species } \\
\text { is present at project site }\end{array}$ & $\begin{array}{l}\text { No Cheat Mountain Salamanders } \\
\text { were found in a search of suitable } \\
\text { habitat onsite. Therefore, it was } \\
\text { determined that the species was not } \\
\text { present. No further action was } \\
\text { taken regarding this species. }\end{array}$ & $\begin{array}{l}\text { Pauley \& } \\
\text { Watson, } 2002\end{array}$ \\
\hline $\begin{array}{l}\text { Biological } \\
\text { Assessment for } \\
\text { Endangered } \\
\text { Bats }\end{array}$ & $\begin{array}{l}\text { - Synthesize information } \\
\text { (habitat survey, data on bat } \\
\text { use of the area, history of } \\
\text { collisions with wind } \\
\text { turbines) to determine } \\
\text { likely effects on Indiana bat } \\
\text { and Virginia big-eared bat }\end{array}$ & $\begin{array}{l}\text { Project site is not suitable foraging } \\
\text { or breeding habitat for either of the } \\
\text { two endangered bat species. } \\
\text { Substantial suitable Indiana bat } \\
\text { habitat is available outside the } \\
\text { project site. } \\
\text { - Potential for endangered bats to } \\
\text { collide with turbines very low to } \\
\text { nonexistent, therefore, "take" } \\
\text { unlikely } \\
\text { - Non-hibernating, long-distance } \\
\text { migratory bats (hoary bat, eastern } \\
\text { red bat, and silver-haired bat) are } \\
\text { most prone to collisions with wind } \\
\text { energy facilities. }\end{array}$ & $\begin{array}{l}\text { Johnson \& } \\
\text { Strickland, } \\
2003\end{array}$ \\
\hline $\begin{array}{l}\text { Supplement to } \\
\text { Biological } \\
\text { Assessment for } \\
\text { Endangered } \\
\end{array}$ & $\begin{array}{l}\text { - Synthesize information } \\
\text { from original biological } \\
\text { assessment combined with } \\
\text { mortality data set from } \\
\end{array}$ & $\begin{array}{l}\text { - Possibility of "take" of an } \\
\text { endangered bat "very remote". } \\
\text { - Review of spotlight and moon } \\
\text { watching surveys (Mabee et al. }\end{array}$ & $\begin{array}{l}\text { Johnson \& } \\
\text { Strickland, } \\
2004\end{array}$ \\
\hline
\end{tabular}




\begin{tabular}{|c|c|c|c|}
\hline Study & Objectives & Results & Reference \\
\hline Bats & $\begin{array}{l}\text { Mountaineer Site and other } \\
\text { eastern wind plants built } \\
\text { near Indiana bat } \\
\text { hibernacula, fall } 2003 \text { avian } \\
\text { radar study combined with } \\
\text { spotlight surveys and moon } \\
\text { watching surveys, cave } \\
\text { location information to } \\
\text { determine likely effects on } \\
\text { Indiana bat and Virginia } \\
\text { big-eared bat }\end{array}$ & $\begin{array}{l}\text { 2004) indicated that bats comprised } \\
\text { about } 6.8 \% \text { of radar "targets" and } \\
\text { were observed only on } 20-30 \% \text { of } \\
\text { nights sampled using spotlights and } \\
20-50 \% \text { of nights sampled using } \\
\text { moon watch surveys } \\
\text { - Incidental observation (Mabee et al. } \\
\text { 2004) indicated that bats may use } \\
\text { valley bottoms rather than the } \\
\text { ridgeline as travel corridors. }\end{array}$ & \\
\hline $\begin{array}{l}\text { Fall Nocturnal } \\
\text { Migration } \\
\text { Radar Study }\end{array}$ & $\begin{array}{l}\text { - Quantify baseline migration } \\
\text { passage rates, flight } \\
\text { altitudes, and flight } \\
\text { directions of nocturnal } \\
\text { passerine migrants during } \\
\text { fall } 2003 \text { (Sept 3-Oct 17) } \\
\text { using radar } \\
\text { - Determine if migrants fly } \\
\text { along Allegheny Front } \\
\text { - Determine variation in } \\
\text { amount and altitude of } \\
\text { migrants at } 3 \text { locations } \\
\text { along ridge }\end{array}$ & $\begin{array}{l}\text { - Fall nocturnal migrants passed at an } \\
\text { average rate of } 199 \text { targets (birds } \\
\text { and bats) per km per hr and an } \\
\text { average altitude of } 410 \mathrm{~m} \text { AGL. } \\
\text { - } 13 \% \text { of fall nocturnal migrants flew } \\
\text { below } 125 \mathrm{~m} \text { AGL, within the rotor- } \\
\text { swept zone. } \\
\text { - Evidence suggests that nocturnal fall } \\
\text { migrants did not fly parallel to the } \\
\text { Allegheny Front ridgeline, but } \\
\text { crossed over it with little or no } \\
\text { change in direction of flight. }\end{array}$ & $\begin{array}{l}\text { Mabee et al., } \\
2004\end{array}$ \\
\hline $\begin{array}{l}\text { Spring and Fall } \\
\text { Diurnal Avian } \\
\text { Fixed-point } \\
\text { Surveys }\end{array}$ & $\begin{array}{l}\text { - Record species } \\
\text { composition, locations, and } \\
\text { habitats with emphasis on } \\
\text { neotropical migrants. } \\
\text { - Quantify relative use by } \\
\text { species, report frequency of } \\
\text { occurrence for each species } \\
\text { for spring, fall, and both } \\
\text { combined. } \\
\text { - Categorize flight heights as }\end{array}$ & $\begin{array}{l}\text { - } 164 \text { species of birds recorded on the } \\
\text { project site. } \\
\text { - Passerines--most numerous group, } \\
\text { comprising } 85 \% \text { of all observations; } \\
\text { raptors--next largest group at } 6.2 \% \text {. } \\
\text { - Avian use showed no correlations } \\
\text { with weather patterns. } \\
\text { - Approximately } 25 \% \text { of the birds } \\
\text { observed during point counts were } \\
\text { flying. }\end{array}$ & $\begin{array}{l}\text { Young et al., } \\
\text { 2003; Young et } \\
\text { al., } 2004\end{array}$ \\
\hline
\end{tabular}




\begin{tabular}{|c|c|c|c|}
\hline Study & Objectives & Results & Reference \\
\hline & $\begin{array}{l}\text { below, within, or above } \\
\text { rotor-swept zone. }\end{array}$ & $\begin{array}{l}\text { - Passerines flew primarily below } \\
\text { rotor-swept zone. } \\
\text { Raptors and other large birds } \\
\text { typically flew within the rotor- } \\
\text { swept zone. }\end{array}$ & \\
\hline $\begin{array}{l}\text { Golden-winged } \\
\text { Warbler Survey }\end{array}$ & $\begin{array}{l}\text { - Determine abundance and } \\
\text { breeding locations for } \\
\text { species in study area }\end{array}$ & $\begin{array}{l}\text { - Although species was present, no } \\
\text { evidence indicated golden-winged } \\
\text { warbler breeding in the project area. }\end{array}$ & $\begin{array}{l}\text { Young et al., } \\
2004\end{array}$ \\
\hline $\begin{array}{l}\text { Breeding } \\
\text { Raptor Survey }\end{array}$ & $\begin{array}{l}\text { - Conduct survey for nesting } \\
\text { raptors in forested areas and } \\
\text { forests with open areas } \\
\end{array}$ & $\begin{array}{l}\text { No active raptor nests found, } \\
\text { probably because of low quality } \\
\text { habitat. }\end{array}$ & $\begin{array}{l}\text { Young et al., } \\
2003\end{array}$ \\
\hline $\begin{array}{l}\text { Winter Bald } \\
\text { Eagle and } \\
\text { Raptor Survey }\end{array}$ & $\begin{array}{l}\text { Estimate spatial and } \\
\text { seasonal use and behavior } \\
\text { by bald eagles (primarily) } \\
\text { and other raptors } \\
\text { (secondarily) }\end{array}$ & $\begin{array}{l}\text { - } 30 \text { raptors observed wintering in } \\
\text { area. } \\
\text { Five of } 30 \text { were bald eagles. These } \\
\text { were all observed along nearby } \\
\text { lakeshores, } 1 \text { to } 2.4 \mathrm{~km} \text { distant from } \\
\text { the nearest proposed turbine site. }\end{array}$ & $\begin{array}{l}\text { Young et al., } \\
2004\end{array}$ \\
\hline $\begin{array}{l}\text { American } \\
\text { Woodcock and } \\
\text { Common Snipe } \\
\text { Surveys }\end{array}$ & $\begin{array}{l}\text { - Survey potential habitat } \\
\text { areas for territorial or } \\
\text { displaying males }\end{array}$ & $\begin{array}{l}\text { Both American woodcock and } \\
\text { common snipe found but not in high } \\
\text { numbers. }\end{array}$ & $\begin{array}{l}\text { Young et al., } \\
2003\end{array}$ \\
\hline
\end{tabular}

AGL. Above-ground level 
Table 3. Potential sources of bias and error in fatality estimates in Tier 4 post-construction assessments (Huso 2011), USFWS (2011), Strickland et al. (2011), Johnson et al. (2000), Manville (2009)

\begin{tabular}{|l|l|}
\hline Source of bias & Bias \\
\hline Periodic sources of mortality & $\begin{array}{l}\text { Leads to inaccurate carcass counts for short time } \\
\text { intervals }\end{array}$ \\
\hline Carcass removal by scavengers & Lowers carcass counts \\
\hline $\begin{array}{l}\text { Unquantified searcher efficiency (intensity, ability) } \\
\text { and variability with time }\end{array}$ & Leads to less predictable carcass counts \\
\hline $\begin{array}{l}\text { Poorly quantified searcher efficiency (e.g., using } \\
\text { carcass that is not representative of desired species }\end{array}$ & Leads to inaccurate fatality rates \\
\hline $\begin{array}{l}\text { Vegetation conditions } \\
\text { Size of search plot }\end{array}$ & $\begin{array}{l}\text { Contributes to uncertainty in carcass removal and } \\
\text { searcher efficiency bias }\end{array}$ \\
\hline Background mortality & Smaller plots lead to incomplete counts, but this is \\
small source of bias compared to others
\end{tabular}


Table 4. Estimated fatality rates, Mount Storm Wind Energy Facility, with 90\% confidence limits. Estimation method modified from Shoenfeld (2004) and Erickson et al. (2003). Data from Young et al. (2009a,b; 2010a,b; 2011a,b; 2012a)

\begin{tabular}{|c|c|c|c|c|c|c|c|}
\hline & Fall 2008 & $\begin{array}{l}\text { Spring } \\
2009\end{array}$ & Fall 2009 & $\begin{array}{l}\text { Spring } \\
2010\end{array}$ & Fall 2010 & $\begin{array}{l}\text { Spring } \\
2011\end{array}$ & $\begin{array}{l}\text { Fall } \\
2011\end{array}$ \\
\hline Study Period & $\begin{array}{l}\text { Jul 18-Oct } \\
17 \\
\text { (91 days) }\end{array}$ & $\begin{array}{l}\text { Mar 23-Jun } \\
14 \\
\text { (84 days) }\end{array}$ & $\begin{array}{l}\text { Jul 16-Oct } \\
8 \\
\text { (84 days) }\end{array}$ & $\begin{array}{l}\text { Apr 16-Jul } \\
14 \\
\text { (89 days) }\end{array}$ & $\begin{array}{l}\text { July } 15- \\
\text { Oct } 15 \\
\text { (93 days) }\end{array}$ & $\begin{array}{l}\text { April 12- } \\
\text { July } 15 \\
\text { (95 days) }\end{array}$ & $\begin{array}{l}\text { July } \\
16-O c t \\
15(80 \\
\left.\text { days }^{1}\right)\end{array}$ \\
\hline \multicolumn{8}{|l|}{ As Reported: } \\
\hline $\begin{array}{l}\text { Birds (avg per } \\
\text { turbine per } \\
\text { study period) } \\
\end{array}$ & $\begin{array}{c}3.81(2.23- \\
5.88)\end{array}$ & $\begin{array}{c}4.15(2.44- \\
6.10)\end{array}$ & $\begin{array}{c}4.59(2.68- \\
6.67)\end{array}$ & $\begin{array}{c}3.97(1.83- \\
5.56)\end{array}$ & $\begin{array}{l}2.77 \\
(2.09- \\
4.47) \\
\end{array}$ & $\begin{array}{r}0.70 \\
(0.54- \\
1.19) \\
\end{array}$ & $\begin{array}{r}7.79 \\
(6.05- \\
11.17) \\
\end{array}$ \\
\hline Large birds ${ }^{2}$ & $\begin{array}{c}1.01(0.00- \\
2.28)\end{array}$ & $\begin{array}{c}0.62(0.00- \\
1.85)\end{array}$ & $\begin{array}{c}0.38(0.00- \\
1.11)\end{array}$ & $\begin{array}{c}1.36(0.41- \\
1.88)\end{array}$ & $\begin{array}{r}0.26 \\
(0.06- \\
0.43) \\
\end{array}$ & $\begin{array}{c}0.06(0- \\
0.17)\end{array}$ & $\begin{array}{r}0.55 \\
(0.26- \\
0.89) \\
\end{array}$ \\
\hline Small birds ${ }^{3}$ & $\begin{array}{c}2.99(1.78- \\
4.89)\end{array}$ & $\begin{array}{c}3.54(2.05- \\
5.05)\end{array}$ & $\begin{array}{c}4.21(2.42- \\
6.34)\end{array}$ & $\begin{array}{c}2.61(0.52- \\
3.94)\end{array}$ & $\begin{array}{r}2.51 \\
(1.84- \\
4.18) \\
\end{array}$ & $\begin{array}{r}0.64 \\
(0.43- \\
1.06) \\
\end{array}$ & $\begin{array}{r}7.23 \\
(5.43- \\
11.35) \\
\end{array}$ \\
\hline $\begin{array}{l}\text { Bats (avg per } \\
\text { turbine per } \\
\text { study period) }\end{array}$ & $\begin{array}{r}24.21 \\
(17.12- \\
33.09) \\
\end{array}$ & $\begin{array}{c}7.45(4.85- \\
10.60)\end{array}$ & $\begin{array}{r}21.11 \\
(13.87- \\
29.92) \\
\end{array}$ & $\begin{array}{c}9.98(8.20- \\
14.06)\end{array}$ & $\begin{array}{c}22.39 \\
(18.41- \\
29.40) \\
\end{array}$ & $\begin{array}{l}5.77 \\
(4.39- \\
6.93) \\
\end{array}$ & $\begin{array}{r}9.10 \\
(7.54- \\
11.38) \\
\end{array}$ \\
\hline \multicolumn{8}{|c|}{ Standardized Units: } \\
\hline $\begin{array}{l}\text { Birds (avg per } \\
\text { MW per study } \\
\text { period) }\end{array}$ & 1.91 & 2.08 & 2.30 & 1.99 & 1.38 & 0.35 & 3.90 \\
\hline $\begin{array}{l}\text { Bats (avg per } \\
\text { MW per study } \\
\text { period) }\end{array}$ & 12.11 & 3.73 & 10.56 & 4.99 & 11.20 & 2.88 & 4.55 \\
\hline
\end{tabular}

Note: Study periods were 3 months. All estimates based on results at turbines searched daily.

${ }^{1} 92$ days minus 12 days that all or some turbines were taken out of service. Data removed for mortality analysis for dates that turbines were out of service

${ }^{2}$ Large birds are defined as raptors, large waterfowl and waterbirds (Strickland et al. 2011).

${ }^{3}$ Small birds are passerines and other comparably-sized birds such as quail (Strickland et al. 2011). 
Table 5. Estimated bat mortality rates and numbers of individual deaths facility-wide, using modified estimation method from Shoenfeld (2004) and Erickson et al. (2003). Data from Young et al. (2009a,b;

2010a,b; 2011a,b; 2012a)

\begin{tabular}{|c|c|c|c|c|c|c|c|}
\hline & Fall 2008 & Spring 2009 & Fall 2009 & Spring 2010 & $\begin{array}{l}\text { Fall } \\
2010 \\
\end{array}$ & $\begin{array}{l}\text { Spring } \\
2011 \\
\end{array}$ & $\begin{array}{l}\text { Fall } \\
2011\end{array}$ \\
\hline $\begin{array}{l}\text { Bat Deaths } \\
\text { (per turbine per } \\
\text { study period) }\end{array}$ & 24.21 & 7.45 & 20.11 & 9.98 & 22.39 & 5.77 & 9.10 \\
\hline $\begin{array}{l}\text { Total Bat } \\
\text { Deaths } \\
\text { Facility-wide }\end{array}$ & 1985 & 983 & 2655 & 1317 & 2955 & 762 & 1201 \\
\hline $\begin{array}{l}\text { Hoary bats } \\
(\% \text { of all bat } \\
\left.\text { deaths }{ }^{1}\right)\end{array}$ & $\begin{array}{c}621 \\
(31.3 \%)\end{array}$ & $\begin{array}{c}274 \\
(27.9 \%)\end{array}$ & $\begin{array}{c}998 \\
(37.6 \%)\end{array}$ & $\begin{array}{c}486 \\
(36.9 \%)\end{array}$ & $\begin{array}{c}748 \\
(25.3 \%)\end{array}$ & $\begin{array}{c}395 \\
(51.9 \%)\end{array}$ & $\begin{array}{c}560 \\
(46.6 \%)\end{array}$ \\
\hline $\begin{array}{l}\text { Eastern red } \\
\text { bats (\% of all } \\
\text { bat deaths) }\end{array}$ & $\begin{array}{c}381 \\
(19.2 \%)\end{array}$ & $\begin{array}{c}69 \\
(7.0 \%)\end{array}$ & $\begin{array}{c}579 \\
(21.8 \%)\end{array}$ & $\begin{array}{c}324 \\
(24.6 \%)\end{array}$ & $\begin{array}{c}1687 \\
(57.1 \%)\end{array}$ & $\begin{array}{c}169 \\
(22.2 \%)\end{array}$ & $\begin{array}{c}408 \\
(34.0 \%)\end{array}$ \\
\hline $\begin{array}{l}\text { Silver-haired } \\
\text { bats (\% of all } \\
\text { bat deaths) }\end{array}$ & $\begin{array}{c}328 \\
(16.5 \%)\end{array}$ & $\begin{array}{c}205 \\
(20.9 \%)\end{array}$ & $\begin{array}{c}353 \\
(13.3 \%)\end{array}$ & $\begin{array}{c}182 \\
(13.8 \%)\end{array}$ & $\begin{array}{c}202 \\
(6.82 \%)\end{array}$ & $\begin{array}{c}99 \\
(13.0 \%)\end{array}$ & $\begin{array}{c}139 \\
(11.6 \%)\end{array}$ \\
\hline $\begin{array}{l}\text { Total of } 3 \\
\text { species } \\
\text { migratory tree } \\
\text { bats killed }\end{array}$ & 1330 & 548 & 1930 & 992 & 2637 & 663 & 1107 \\
\hline
\end{tabular}

Note: Estimates include only deaths during each study period. Studies are timed to include periods of maximum mortality.

${ }^{1}$ Percentages are percentages of the species found in scheduled searches. Species totals represent percentages multiplied by total bat death estimate across 132 turbines 
Table 6. Bird fatality rates (fatalities/MW/yr) from Mount Storm Wind Energy Facility and nearby wind energy projects

\begin{tabular}{|l|l|l|l|l|l|l|}
\hline & $\begin{array}{l}\text { Estimated } \\
\text { fatality rate }\end{array}$ & $\begin{array}{l}\text { Total } \\
\text { MW }\end{array}$ & $\begin{array}{l}\text { Number } \\
\text { of } \\
\text { turbines }\end{array}$ & $\begin{array}{l}\text { Turbine } \\
\text { type }\end{array}$ & $\begin{array}{l}\text { Tower } \\
\text { height }\end{array}$ & $\begin{array}{l}\text { Rotor swept } \\
\text { area }\end{array}$ \\
\hline Mount Storm $^{1}$ & 4.0 & 264 & 132 & $\begin{array}{l}\text { G-80 } \\
\text { Gamesa }\end{array}$ & $78 \mathrm{~m}$ & $5027 \mathrm{~m}^{2}$ \\
\hline Casselman $^{2}$ & 1.5 & 34.5 & 23 & GE SLE & $80 \mathrm{~m}$ & $4657 \mathrm{~m}^{2}$ \\
\hline Mountaineer $^{3}$ & 3.2 & 66 & 44 & $\begin{array}{c}72 \mathrm{C} \mathrm{Neg} \\
\text { Micon }\end{array}$ & $70 \mathrm{~m}$ & $4072 \mathrm{~m}^{2}$ \\
\hline
\end{tabular}

${ }^{1}$ Assumes that mortality only occurs during spring and fall study periods, a reasonable assumption if birds are only resident during those periods. Average for data from 2009, 2010, and 2011 (Young et al. 2009b, 2010a,b; 2011a,b; 2012).

${ }^{2}$ Assumes that mortality only occurs during spring, summer, and fall study periods, a reasonable assumption if birds are only resident during those periods. Data from 2008 (Arnett et al. 2009b).

${ }^{3}$ Assumes that mortality only occurs during spring, summer, and fall study periods, a reasonable assumption if birds are only resident during those periods. Data from 2003 (Kerns and Kerlinger 2004). 
Table 7. Bat fatality rates from Mount Storm and nearby wind energy facilities

\begin{tabular}{|c|c|c|c|c|c|c|c|}
\hline & Study period & $\begin{array}{l}\text { Estimated } \\
\text { Fatalities } \\
\text { per MW }\end{array}$ & $\begin{array}{l}\text { Total } \\
\text { MW }\end{array}$ & $\begin{array}{l}\text { Number } \\
\text { of } \\
\text { Turbines } \\
\end{array}$ & $\begin{array}{l}\text { Turbine } \\
\text { Type }\end{array}$ & $\begin{array}{l}\text { Tower } \\
\text { height }\end{array}$ & $\begin{array}{l}\text { Rotor } \\
\text { Swept } \\
\text { Area } \\
\end{array}$ \\
\hline \multirow[t]{7}{*}{ Mount Storm } & $\begin{array}{l}\text { July } 18 \text { - October } \\
17,2008\end{array}$ & 12.11 & 164 & 82 & \multirow{7}{*}{$\begin{array}{l}\text { G-80 } \\
\text { Gamesa }\end{array}$} & \multirow{7}{*}{$78 \mathrm{~m}$} & \multirow{7}{*}{$\begin{array}{l}5027 \\
\mathrm{~m}^{2}\end{array}$} \\
\hline & $\begin{array}{l}\text { March } 23 \text { - June } \\
14,2009\end{array}$ & 3.73 & 264 & 132 & & & \\
\hline & $\begin{array}{l}\text { July } 16 \text { - October } \\
8,2009\end{array}$ & 10.56 & 264 & 132 & & & \\
\hline & $\begin{array}{l}\text { April } 16 \text { - July 14, } \\
2010\end{array}$ & 4.99 & 264 & 132 & & & \\
\hline & $\begin{array}{l}\text { July } 15 \text { - October } \\
15,2010\end{array}$ & 11.20 & 264 & 132 & & & \\
\hline & $\begin{array}{l}\text { April } 12 \text { - July } \\
15,2011\end{array}$ & 2.88 & 264 & 132 & & & \\
\hline & $\begin{array}{l}\text { July } 16 \text { - October } \\
15,2011\end{array}$ & 4.55 & 264 & 132 & & & \\
\hline $\begin{array}{l}\text { Casselman } \\
\text { (Arnett et al, } \\
\text { 2009a) }\end{array}$ & $\begin{array}{l}\text { April - November } \\
2008\end{array}$ & 21.5 & 34.5 & 23 & GE SLE & $80 \mathrm{~m}$ & $\begin{array}{l}4657 \\
\mathrm{~m}^{2}\end{array}$ \\
\hline $\begin{array}{l}\text { Meyersdale } \\
\text { (Kerns et al., } \\
2005)\end{array}$ & $\begin{array}{l}\text { August - } \\
\text { September } 2004\end{array}$ & 15.3 & 30 & 20 & $\begin{array}{l}72 \mathrm{C} \mathrm{Neg} \\
\text { Micon }\end{array}$ & $80 \mathrm{~m}$ & $\begin{array}{l}4072 \\
\mathrm{~m}^{2}\end{array}$ \\
\hline \multirow{2}{*}{$\begin{array}{l}\text { Mountaineer } \\
\text { (Kerns \& } \\
\text { Kerlinger, } \\
\text { 2004, Kerns et } \\
\text { al. 2005) }\end{array}$} & $\begin{array}{l}\text { April - November } \\
2003\end{array}$ & 32.0 & 66 & 44 & \multirow{2}{*}{$\begin{array}{l}72 \mathrm{C} \mathrm{Neg} \\
\text { Micon }\end{array}$} & \multirow[b]{2}{*}{$70 \mathrm{~m}$} & \multirow{2}{*}{$\begin{array}{l}4072 \\
\mathrm{~m}^{2}\end{array}$} \\
\hline & $\begin{array}{l}\text { July - September } \\
2004\end{array}$ & 25.2 & 66 & 44 & & & \\
\hline
\end{tabular}

Estimates from all sites have been adjusted for searcher efficiency and scavenging rates using estimator from Shoenfeld (2004) and Erickson et al. (2004). 


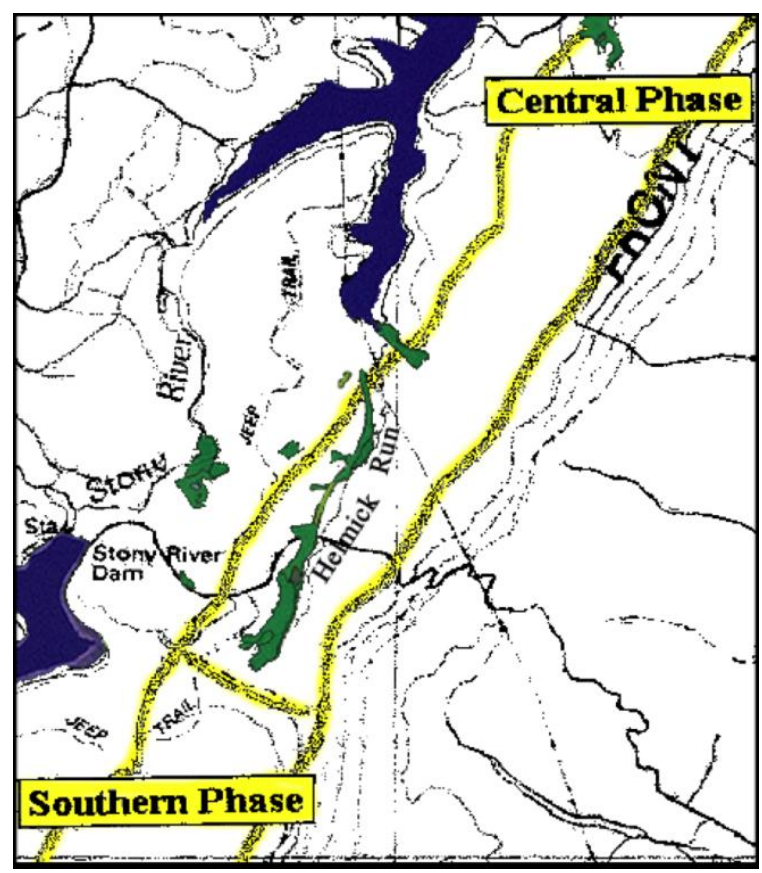

Figure 1. Helmick Run Bog. Sources: 1) NedPower Mount Storm, 2002, p. 29. 2) USFWS National Wetlands Inventory, Wetlands Mapper at http://www.fws.gov/wetlands/Data/Mapper.html 


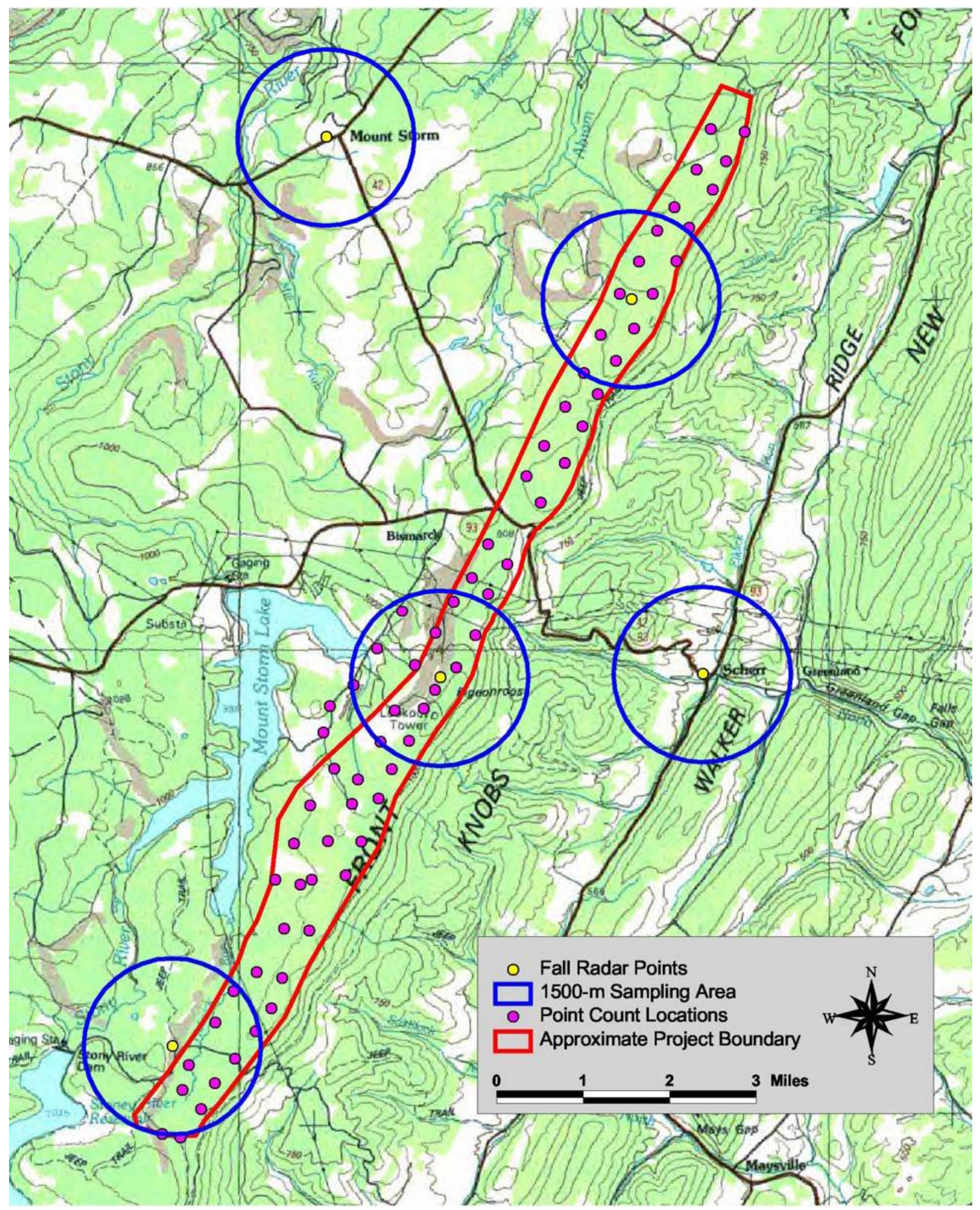

Figure 2. Radar sampling station locations and fixed-point survey plot locations, taken from the avian baseline assessment for Mount Storm, Young et al. (2004). 


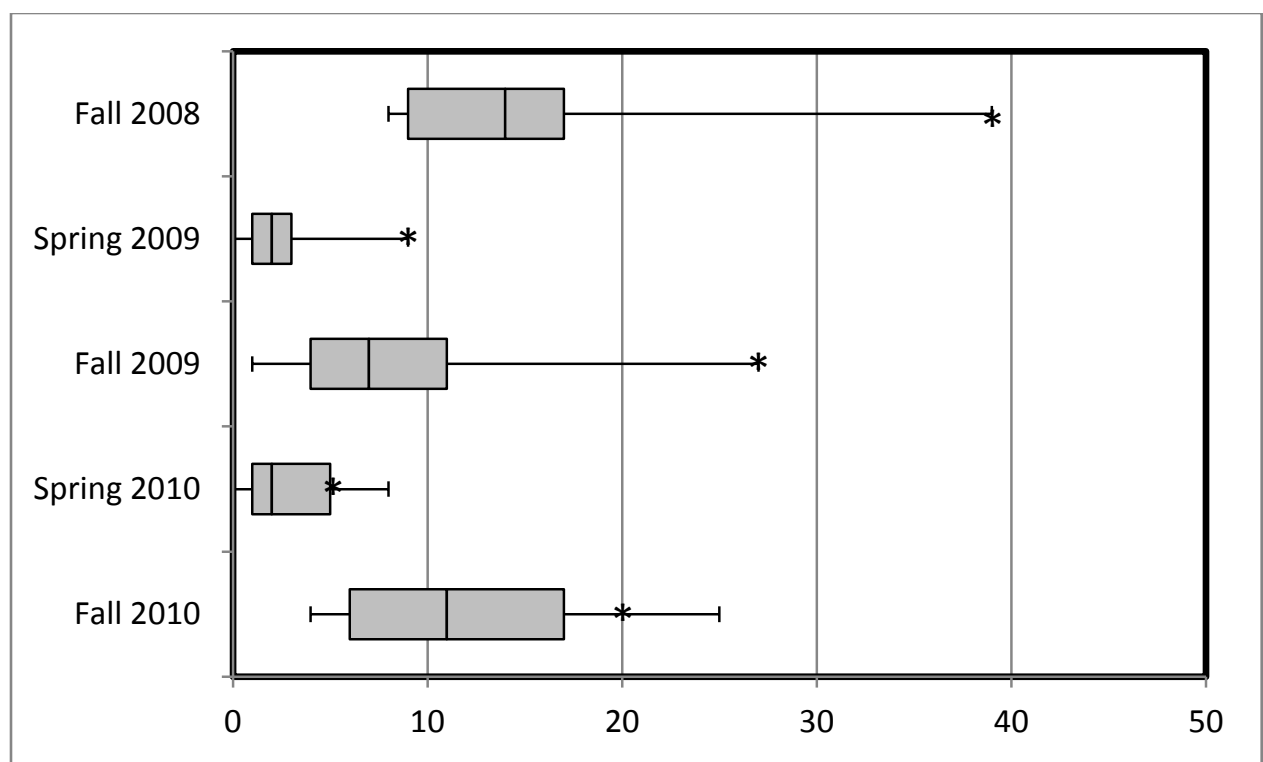

Figure 3. Numbers of bat carcasses found at turbines searched daily. Box and whiskers plots show median, lower quartile, upper quartile, and extremes. Asterisks show Turbine 81. For Fall 2008, Spring 2009, and Fall 2009, Turbine 81 was an extreme outlier for bat fatalities, using the conservative definition of three times the interquartile range. Turbine 81 was not included in daily searches in spring or fall of 2011; therefore it is unknown if it would have been an outlier during those seasons. 